\title{
Claudin-2 deficiency associates with hypercalciuria in mice and human kidney stone disease
}

\author{
Joshua N. Curry, ${ }^{1,2}$ Matthew Saurette, ${ }^{3,4}$ Masomeh Askari, ${ }^{5}$ Lei Pei, ${ }^{6}$ Michael B. Filla, ${ }^{2,6}$ Megan R. Beggs, ${ }^{3,4}$ Peter S.N. Rowe, ${ }^{2,6}$ \\ Timothy Fields, ${ }^{7}$ Andre J. Sommer, ${ }^{8}$ Chizu Tanikawa, ${ }^{9}$ Yoichiro Kamatani, ${ }^{10}$ Andrew P. Evan, ${ }^{11}$ Mehdi Totonchi, ${ }^{5,12}$ \\ R. Todd Alexander, ${ }^{4,13}$ Koichi Matsuda, ${ }^{9,14}$ and Alan S.L. Yu ${ }^{1,2,6}$
}

\begin{abstract}
'Department of Molecular and Integrative Physiology and ${ }^{2}$ Jared Grantham Kidney Institute, University of Kansas Medical Center, Kansas City, Kansas, USA. ${ }^{3}$ Department of Pediatrics and ${ }^{4}$ Membrane Protein Disease Research Group, University of Alberta, Edmonton, Alberta, Canada. ${ }^{5}$ Department of Genetics, Reproductive Biomedicine Research Center, Royan Institute for Reproductive Biomedicine, Academic Center for Education, Culture and Research (ACECR), Tehran, Iran. ${ }^{6}$ Division of Nephrology and Hypertension, Department of Internal Medicine, and ${ }^{7}$ Department of Pathology and Laboratory Medicine, University of Kansas Medical Center, Kansas City, Kansas, USA. ${ }^{8}$ Department of Chemistry and Biochemistry, Miami University, Oxford, Ohio, USA. ${ }^{9}$ Laboratory of Cenome Technology, Human Cenome Center, Institute of Medical Science, Graduate School of Frontier Sciences, University of Tokyo, Tokyo, Japan. ${ }^{10}$ Laboratory for Statistical Analysis, RIKEN Center for Integrative Medical Sciences, Kanagawa, Japan. "Department of Anatomy and Cell Biology, Indiana University School of Medicine, Indianapolis, Indiana, USA. ${ }^{2}$ Department of Stem Cells and Developmental Biology, Cell Science Research Center, Royan Institute for Stem Cell Biology and Technology, ACECR, Tehran, Iran. ${ }^{3}$ Department of Physiology, University of Alberta, Edmonton, Alberta, Canada. ${ }^{14}$ Laboratory of Clinical Genome Sequencing, Department
\end{abstract} of Computational Biology and Medical Sciences, Graduate School of Frontier Sciences, University of Tokyo, Tokyo, Japan.

\begin{abstract}
The major risk factor for kidney stone disease is idiopathic hypercalciuria. Recent evidence implicates a role for defective calcium reabsorption in the renal proximal tubule. We hypothesized that claudin-2, a paracellular cation channel protein, mediates proximal tubule calcium reabsorption. We found that claudin-2-null mice have hypercalciuria due to a primary defect in renal tubule calcium transport and papillary nephrocalcinosis that resembles the intratubular plugs in kidney stone formers. Our findings suggest that a proximal tubule defect in calcium reabsorption predisposes to papillary calcification, providing support for the vas washdown hypothesis. Claudin-2-null mice were also found to have increased net intestinal calcium absorption, but reduced paracellular calcium permeability in the colon, suggesting that this was due to reduced intestinal calcium secretion. Common genetic variants in the claudin-2 gene were associated with decreased tissue expression of claudin-2 and increased risk of kidney stones in 2 large population-based studies. Finally, we describe a family in which males with a rare missense variant in claudin-2 have marked hypercalciuria and kidney stone disease. Our findings indicate that claudin- 2 is a key regulator of calcium excretion and a potential target for therapies to prevent kidney stones.
\end{abstract}

\section{Introduction}

Kidney stone disease is common, with a lifetime risk in the United States of about $19 \%$ in men and $9 \%$ in women (1). Studies of families (2), twin concordance (3), and genome-wide association (4-6) have revealed a significant role for polygenic inheritance in the pathogenesis of the disease. The vast majority of stones are composed of calcium crystals, primarily calcium phosphate or calcium oxalate $(\mathrm{CaOx})(7,8)$, and the major risk factor is an elevation in urine calcium, which is termed idiopathic hypercalciuria (9). Additional risk factors for kidney stone formation include low urine volume, hyperoxaluria, and hypocitraturia (9). The common pathogenic factor in these metabolic abnormalities is supersaturation of calcium salts leading to precipitation and crystal growth (9).

The pathogenesis of stone formation in patients with idiopathic hypercalciuria varies depending on the composition of the stone, but the majority are believed to begin with deposition of calcium within the renal papilla, or papillary nephrocalcinosis (8).

Conflict of interest: The authors have declared that no conflict of interest exists. Copyright: (5) 2020, American Society for Clinical Investigation.

Submitted: February 1, 2019; Accepted: January 8, 2020; Published: March 9, 2020.

Reference information: / Clin Invest. 2020;130(4):1948-1960.

https://doi.org/10.1172/JCl127750.
For patients with urinary stones composed of primarily $\mathrm{CaOx}$, the precursor lesions are known as Randall's plaques and are characterized by deposition of calcium phosphate within the interstitial space surrounding the basement membranes of the thin limbs of loops of Henle $(10,11)$. By contrast, patients with predominantly calcium phosphate urinary stones often have early intratubular calcium phosphate deposits in inner medullary collecting ducts, as well as interstitial aggregates of calcium phosphate, termed novel interstitial plaque structures, that have microscopic features distinct from Randall's plaques (8). All of these forms of intrarenal deposits are believed to eventually rupture through the papillary surface and thereby form a nidus for the growth of urinary stones.

The etiology of idiopathic hypercalciuria is incompletely understood, but can generally be ascribed to increased bone resorption, intestinal hyperabsorption, and/or reduced renal reabsorption of calcium (12). Studies of diuretic response and lithium clearance in patients with idiopathic hypercalciuria suggest that they have a specific defect in calcium reabsorption in the proximal renal tubule (PT) $(13,14)$. The PT reabsorbs approximately $60 \%$ of calcium filtered by the glomerulus (15). It is highly permeable to calcium, and the tubule fluid/plasma concentration ratio is about 1.1, suggesting that transport of calcium follows that of sodium and water (15). In isolated perfused PTs from the pars convoluta, net calcium trans- 
Table 1. Serum and urinary parameters of male mice on standard lab chow

\begin{tabular}{|c|c|c|c|c|c|c|c|}
\hline \multirow[t]{2}{*}{ Parameter } & \multicolumn{3}{|c|}{ Wild type } & \multicolumn{3}{|c|}{ Cldn2-/y } & \multirow[t]{2}{*}{$P$ value } \\
\hline & Mean & SEM & $n$ & Mean & SEM & $n$ & \\
\hline \multicolumn{8}{|l|}{ Serum } \\
\hline Calcium (mg/dL) & 10.24 & 0.17 & 9 & 10.74 & 0.43 & 8 & 0.27 \\
\hline 1,25-Dihydroxyvitamin D (pmol/L) & 193 & 13 & 8 & 201 & 21 & 8 & 0.74 \\
\hline PTH (pg/mL) & 696 & 158 & 11 & 699 & 134 & 10 & 0.99 \\
\hline \multicolumn{8}{|l|}{ Urine } \\
\hline FECa (\%) & 0.23 & 0.02 & 8 & 0.40 & 0.02 & 7 & 0.0001 \\
\hline Phosphorus/Cr (mg/mg) & 7.73 & 1.64 & 8 & 6.65 & 1.76 & 5 & 0.67 \\
\hline Oxalate/Cr (mg/mg) & 0.09 & 0.01 & 5 & 0.12 & 0.01 & 4 & 0.22 \\
\hline Citrate/Cr (mg/mg) & 6.79 & 0.58 & 8 & 7.11 & 0.95 & 5 & 0.76 \\
\hline $\mathrm{Mg} / \mathrm{Cr}(\mathrm{mg} / \mathrm{mg})$ & 3.57 & 0.20 & 8 & 3.11 & 0.25 & 5 & 0.18 \\
\hline
\end{tabular}

PTH, parathyroid hormone; FECa, fractional excretion of calcium; $\mathrm{Cr}$, creatinine. satory changes in expression of calcium transporters in more distal segments of the nephron. We previously showed that expression of claudin-16, claudin-19, and the Na-K-2Cl cotransporter (NKCC2) is unchanged (23). We now show that expression of calbindin-D28k, the apical calcium entry channel TRPV5, the Na-Ca exchanger NCX1, and claudin-14 was also not different between Cldn2-/y and WT mice (Supplemental Figure 1).

Increased net intestinal absorption of calcium in Cldn2-/y mice. If the hypercalciuria in $C l d n 2^{-/ y}$ mice is solely due to primary renal calcium wasting, we would expect them to be in negative calcium balance

port is zero in the absence of osmotic or potential differences, and reabsorption can be induced by application of a lumen-positive potential difference (16). This suggests that calcium reabsorption in the PT is passive and likely occurs by paracellular diffusion.

Paracellular transport is mediated by a family of tetraspanning membrane proteins known as claudins that are found at the tight junction between epithelial cells. These proteins act as chargeselective channels or barriers regulating the movement of solutes across epithelial layers (17). Claudin-2 is a cation-selective isoform $(18,19)$ that is permeable to both sodium and calcium $(19,20)$ and is highly expressed in the PT and the descending thin limb of the loop of Henle (21). Isolated PTs from claudin-2-knockout mice have increased transepithelial resistance and reduced sodium permeability, and exhibit increased fractional excretion of calcium $\left(\mathrm{FECa}^{2+}\right)(22)$, suggesting that claudin-2 mediates paracellular calcium reabsorption in the PT.

In this study we tested the hypothesis that loss of claudin-2 predisposes mice to nephrocalcinosis and nephrolithiasis, mimicking the pathogenesis of human kidney stone disease. We explored the underlying mechanism and tested whether variants in the claudin-2 gene are associated with human kidney stone disease.

\section{Results}

Deletion of Cldn2 in mice causes hypercalciuria due to defective renal tubular calcium reabsorption. We first confirmed that claudin-2knockout mice (Cldn2-/y) are hypercalciuric. $\mathrm{FECa}^{2+}$ was increased in $C l d n 2^{-y}$ mice compared with their WT littermates (Table 1$)$. There was no significant difference in serum calcium levels (Table 1), and we previously showed that glomerular filtration rate is unchanged in Cldn2-y mice (23). Hence, the filtered load of calcium is unchanged. This suggests that renal tubule calcium reabsorption is decreased in $C l d n 2^{-/ y}$ mice. As claudin- 2 is predominantly expressed in the PT and is permeable to calcium (20), these results suggest that $\mathrm{Cldn2^{-/y }}$ mice are hypercalciuric as a result of impaired PT paracellular calcium transport. Our urine calcium studies were replicated in a separate experiment that showed that both male Cldn $2^{-y}$ and female Cldn2-/ mice were similarly hypercalciuric (Supplemental Table 1; supplemental material available online with this article; https:/doi. org/10.1172/JCI127750DS1). We found no evidence for compen- and hence to exhibit a compensatory increase in the calciotropic hormones parathyroid hormone (PTH) and 1,25(OH) $)_{2}$-vitamin $\mathrm{D}_{3}$ (24). However, there were no significant differences in the levels of these hormones (Table 1). We would also expect Cldn2-/y mice to have net calcium loss from bone. However, we found no detectable difference in either total or lumbar bone mineral density in male $C l d n 2^{-/ y}$ mice, on either a normal or a low-calcium diet (Figure 1). Micro-CT analysis of femurs from 10-week-old animals confirmed normal bone volume and quality (Figure $1 \mathrm{C}$ and Supplemental Table 2). The finding that there was no change in the levels of PTH, 1,25(OH) $)_{2}$-vitamin $\mathrm{D}_{3}$, and bone mineral density in $C l d n 2^{-/ y}$ mice despite marked hypercalciuria suggests that they may have a concurrent primary increase in net intestinal absorption of calcium. Indeed, concurrent renal calcium wasting and intestinal hyperabsorption of calcium is typical of idiopathic hypercalciuria in patients with kidney stones and in hypercalciuric rats $(12,25)$. Moreover, claudin-2 is known to be expressed in intestinal epithelial cells.

To test the hypothesis that there is also a primary increase in intestinal absorption of calcium in $C l d n 2^{-/ y}$ mice, we determined whether the hypercalciuria was attenuated by a reduction in dietary calcium content. We placed animals in metabolic cages on a control diet $(0.6 \%$ calcium $)$, and after 5 days switched half of them to a calcium-deficient $(<0.01 \%$ calcium) diet (Figure $2 \mathrm{~A})$. We found that urinary calcium excretion in $C l d n 2^{-y y}$ mice is highly sensitive to dietary calcium intake (Figure 2A). On the control diet, $\mathrm{FECa}^{2+}$ in $\mathrm{Cldn2}^{-/ y}$ mice was approximately 5 times higher than in WT mice $(1.37 \%$ vs. $0.28 \%)$ (Figure $2 \mathrm{~B})$. In contrast, the $\mathrm{FECa}^{2+}$ of $\mathrm{Cldn}^{-/ y}$ mice on the calcium-deficient diet was only twice that of WT mice (0.44\% vs. $0.23 \%)$ (Figure $2 \mathrm{~B})$. No differences in serum calcium, phosphorus, or PTH were found between the groups (Figure 2, C-E).

These results suggest that hypercalciuria in $C l d n 2^{-/ y}$ mice is due to increased net intestinal absorption of calcium, in addition to a primary renal calcium leak. To confirm this, we performed metabolic balance studies over a 3-day period on the control diet (0.6\% calcium) (Figure 3, A-C). As expected, renal calcium excretion was increased in $C l d n 2^{-/ y}$ mice. Intestinal calcium absorption, determined from the difference between dietary calcium intake 
A

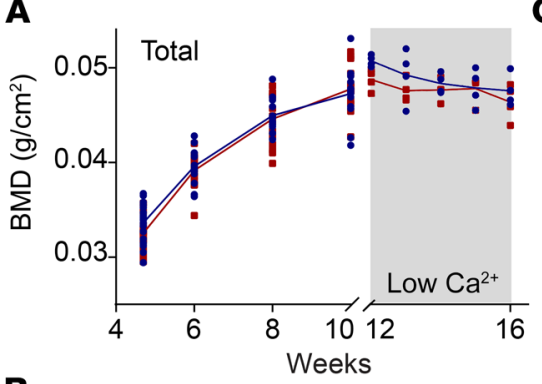

B

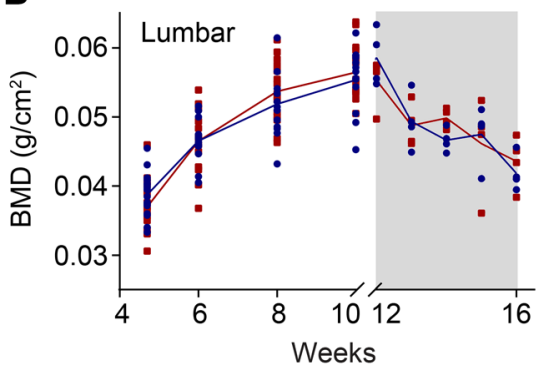

C
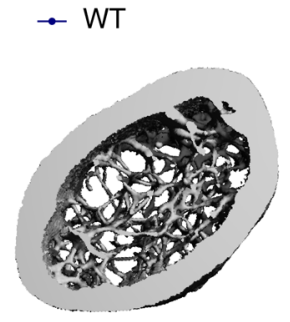

$-C / d n 2^{-y}$

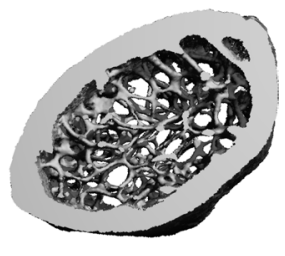

D

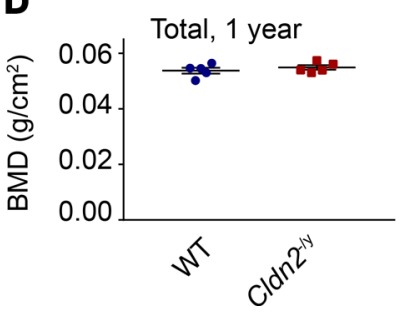

E

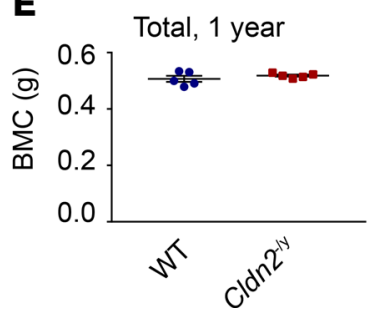

and fecal calcium content, was greater in $\mathrm{Cldn2^{-/y }}$ mice $(5.3 \%$ $\pm 4.2 \%$ of intake $)$ than in WT mice $(-2.3 \% \pm 7.5 \%$ of intake; $P<$ $0.05)$. As a consequence, net calcium balance was more positive in Cldn2-/y mice than in WT mice. On the calcium-deficient diet (Figure 3, D-F), fecal calcium exceeded dietary intake, so that there was net intestinal secretion of calcium, which was decreased in magnitude in the Cldn2-y mice. Net calcium balance was markedly negative. Nevertheless, $C l d n 2^{-/ y}$ mice were still hypercalciuric compared with WT mice, indicating that a primary renal calcium leak had been unmasked.

Cldn2- $2^{-y}$ mice have decreased colonic permeability to calci$u m$. To elucidate the mechanism for increased net intestinal absorption of calcium in $\mathrm{Cldn2}^{-/ y}$ mice, the calcium permeability of different intestinal segments was determined from unilateral, serosal-to-mucosal ${ }^{45} \mathrm{Ca}$ tracer flux assays in ex vivo everted gut sacs (Figure 4). Because there is no known active secretory mechanism for calcium in intestinal epithelium, the serosal-to-mucosal flux should represent passive and pre-

Figure 2. Hypercalciuria in Cldn2 ${ }^{-/ y}$ mice is sensitive to dietary calcium intake. (A) Metabolic cage experiments show 24-hour urine calcium $\left(\mathrm{Ca}^{2+}\right)$ excretion on control diet until day 5 , after which half of the animals ( $n=5-7$ per group) are switched to a calcium-deficient diet $(<0.01 \%$ calcium $)$. At day 10 , the experiment was terminated and serum was collected. (B) Fractional excretion of calcium (FECa) at day 10. (C-E) Serum $\mathrm{Ca}^{2+}(\mathbf{C})$, serum inorganic phosphorus (D), and serum intact parathyroid hormone (1-84) (E) at day 10 . Bars are mean \pm SEM. ${ }^{*} P<$ $0.05,{ }^{* * *} P<0.0001$ using 2-way ANOVA with Bonferroni's correction for multiple comparisons.

Figure 1. Bone mineral metabolism is normal in Cldn2 ${ }^{-/ y}$ mice. Bone analysis of WT (blue) and Cldn2-/y (red) animals on a standard chow diet. (A and B) Total (A) and lumbar (B) bone mineral density (BMD) was measured using DEXA at $4.7,6,8$, and 10 weeks ( $n=14-18$ per group). A group of these animals was started on a low-calcium diet for 4 weeks and BMD measured weekly ( $n=4$ per group). (C) Representative micro-CT reconstructions of femurs showing normal cortical and trabecular bone in Cldn2 $2^{-1 y}$ mice. ( $\mathbf{D}$ and $\mathbf{E}$ ) Total BMD (D) and total bone mineral content (BMC) (E) were measured in 1-year-old animals by DEXA ( $n=5$ per group). There were no significant differences between groups using unpaired 2 -tailed $t$ test. Bars are mean \pm SEM

sumably paracellular transepithelial permeability. There was no difference in the serosal-to-mucosal flux and permeability of the duodenum and ileum. However, the colonic serosal-to-mucosal flux and permeability were significantly reduced in $\mathrm{Cldn2^{-/y }}$ mice. Moreover, mucosal-to-serosal flux in the colon was very similar to serosal-to-mucosal flux (i.e., net flux was negligible) (Figure 4B), indicating that the measured fluxes represent passive transport, and was reduced similarly in $\mathrm{Cldn2^{-/y }}$ mice, as would be expected for an effect on the paracellular pathway.

To confirm these findings, we mounted full-thickness segments of proximal colon in Ussing chambers and determined their ionic permeability from equilibrium potential measurements. As expected, colons from $\mathrm{Cldn2^{-/y }}$ mice had significantly lower permeability to $\mathrm{Na}^{+}\left(\mathrm{P}_{\mathrm{Na}}\right)$ and $\mathrm{Ca}^{2+}\left(\mathrm{P}_{\mathrm{Ca}}\right)$ and permeability ratio of $\mathrm{Na}^{+}$ to $\mathrm{Cl}^{-}\left(\mathrm{P}_{\mathrm{Na}} / \mathrm{P}_{\mathrm{Cl}}\right)$ than colons of WT male littermates (Figure 5). In experiments comparing full-thickness preparations with colon stripped of its seromuscular layer, we found no differences in ion permeability (Supplemental Table 3). Additionally, we confirmed that stripped proximal colon segments from female $\mathrm{Cldn} 2^{-/}$mice
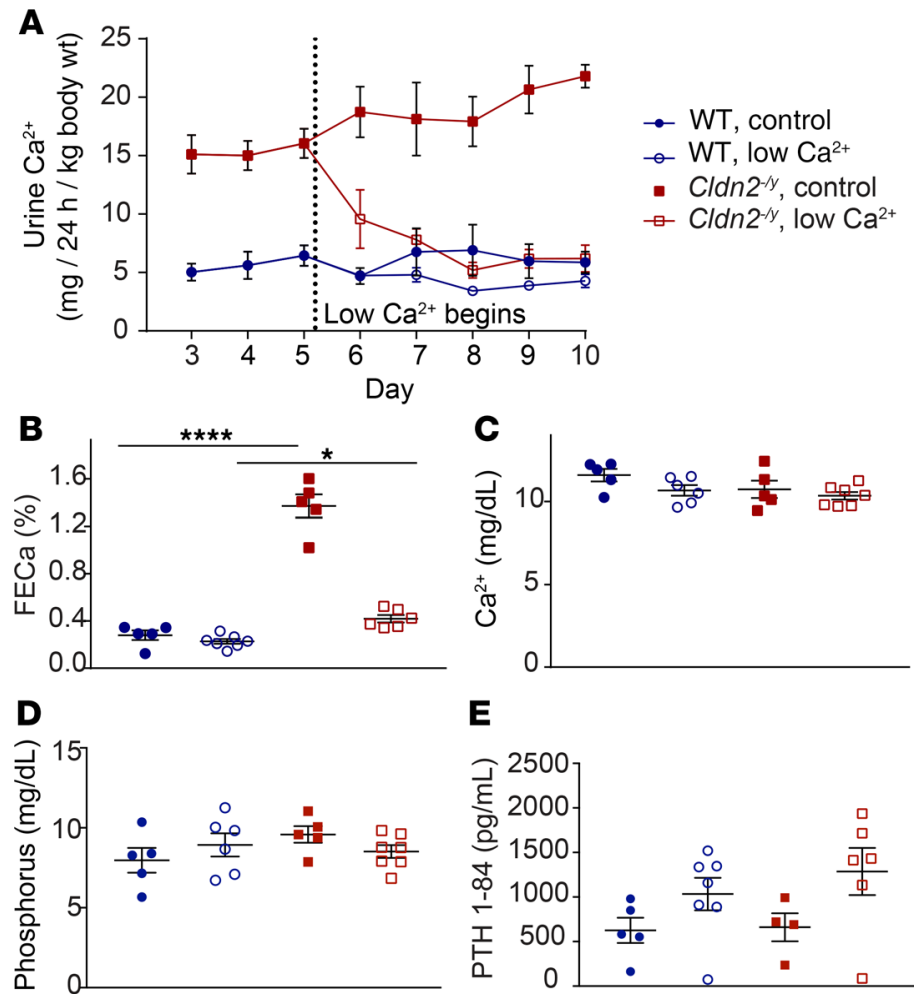
A
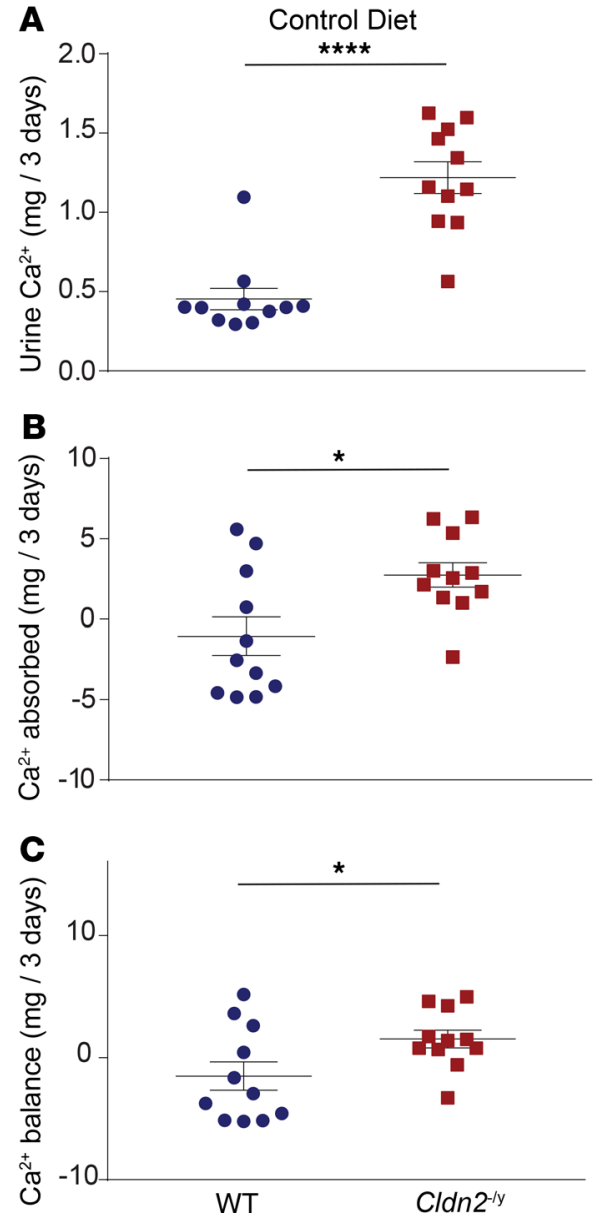
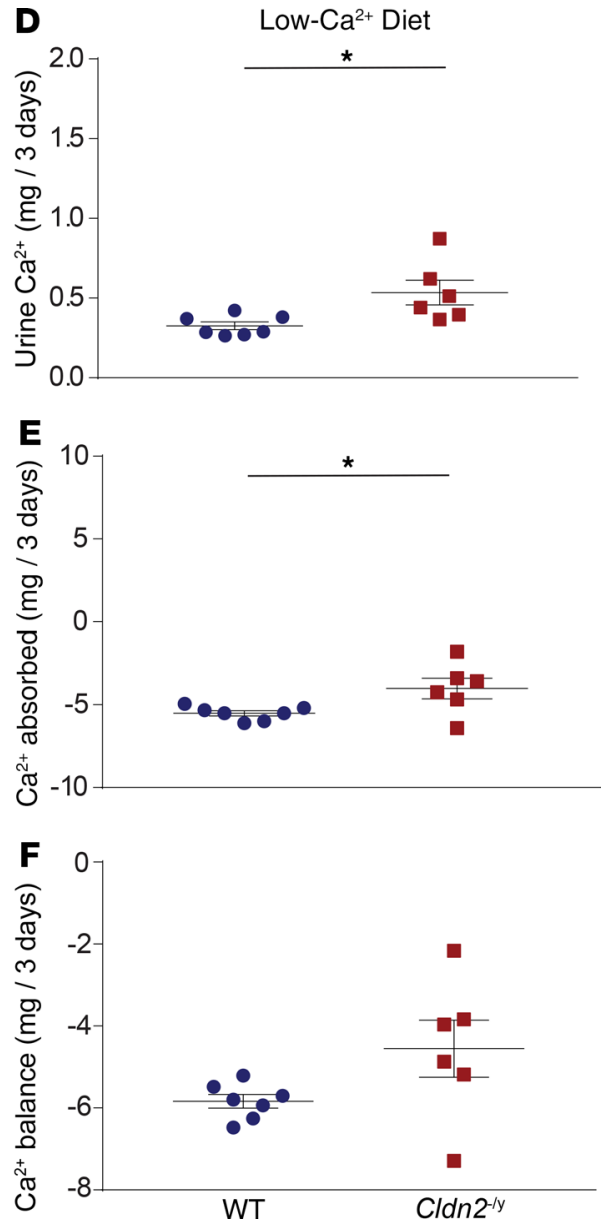

Figure 3. Calcium balance studies in Cldn2 $^{-/ y}$ mice and WT controls. Mice were housed in metabolic cages for 3 days, during which urine and feces were collected for measurement of calcium, and dietary consumption determined by weighing of the food. (A-C) Normal-calcium (0.6\%) diet ( $n=11$ per group). (D-F) Calcium-deficient $(<0.01 \%)$ diet ( $n=6-7$ per group). (A and $\mathbf{D})$ Total 3-day urinary calcium excretion. (B and E) Total 3-day intestinal calcium absorption (calcium consumed minus fecal calcium content). (C and F) Net calcium balance (intestinal absorption minus urinary excretion). Bars are mean $\pm \mathrm{SEM} .{ }^{*} P<0.05,{ }^{*}{ }^{* *} P<$ 0.0001 using unpaired 2 -tailed $t$ test. had reduced permeability to calcium in comparison with WT animals (Supplemental Table 4).

The expression levels of intestinal epithelial transcellular transport proteins, including TRPV6, calbindin-D9k, and plasma membrane calcium ATPase- 1 , and of the intestinal paracellular cation channel proteins claudin-12 and -15, were no different between the genotypes (Supplemental Figure 2). Taken together with the calcium balance studies, these findings suggest that loss of claudin-2 leads to a reduction in paracellular permeability to calcium in the colon, and hence to a reduction in passive secretion of calcium in the distal intestine.

Cldn2-y mice exhibit marked papillary nephrocalcinosis. Hypercalciuria is a major risk factor for nephrocalcinosis, the precipitation of calcium deposits within the kidney parenchyma and tubules, and the formation of kidney stones (8). We observed abundant mineral deposits in the renal papilla of 6-month-old $C l d n 2^{-/ y}$ mice that stained with von Kossa stain and alizarin red S at $\mathrm{pH} 4.2$ (26), and alizarin red-stained deposits were birefringent under polarized light. These findings are suggestive of the presence of calcium phosphate (Figure 6, A-C). Micro-Fourier transform infrared spectroscopy (micro-FTIR) confirmed the composition as primarily calcium phosphate in the form of hydroxyapatite, with a small amount of calcium carbonate (Figure 6D). Transmission electron microscopy (TEM) revealed large, circular, laminated mineral deposits typical of hydroxyapatite (Figure 6E). These deposits appeared to be surrounded by a basement membrane, although no intact epithelium could be identified in the sections. There was scant mineral in WT kidneys at all age groups examined. None of the Cldn2-y mice had papillary deposits at 4.5 months, but all had developed papillary deposition at 6 months and 1 year (Figure 6, F and G). Additionally, Cldn2 $2^{-/-}$females developed similar papillary deposits (Supplemental Figure 3).

We used a combination of von Kossa and immunofluorescence staining to determine the localization of these deposits. No deposits were found within inner medullary collecting ducts or the vasa recta (Figure 7, A and C). Occasional deposits were observed within the lumen of aquaporin-1-positive (AQP1-positive) descending thin limbs or kidney-specific chloride channel-positive (CLC-Kpositive) ascending thin limbs of the loops of Henle (Figure 7, A and $\mathrm{B}$, arrow). However, the vast majority of deposits did not associate with any epithelial or endothelial markers, suggesting either that they formed in the interstitium or that they originated within tubules that subsequently degenerated. The diameter of the calcium deposits on histological cross sections and micro-CT reconstructions was approximately $20 \mu \mathrm{m}$ (Supplemental Figure 4), similar to the diameter of thin limbs of the loops of Henle (27). To detect earlier deposits, we examined the papillae of 5-monthold $C l d n 2^{-/ y}$ mice by TEM. Early calcium deposits in these mice were detected within lumina of intact tubules with type 4 cells of ascending thin limbs of the loops of Henle, identifiable by their extensive lateral interdigitations (Figure 7D), as well as type 3 cells of descending thin limbs of the loops of Henle, characterized by 

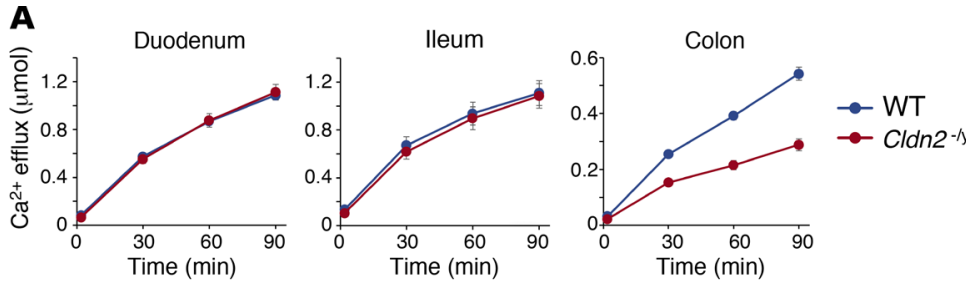

B

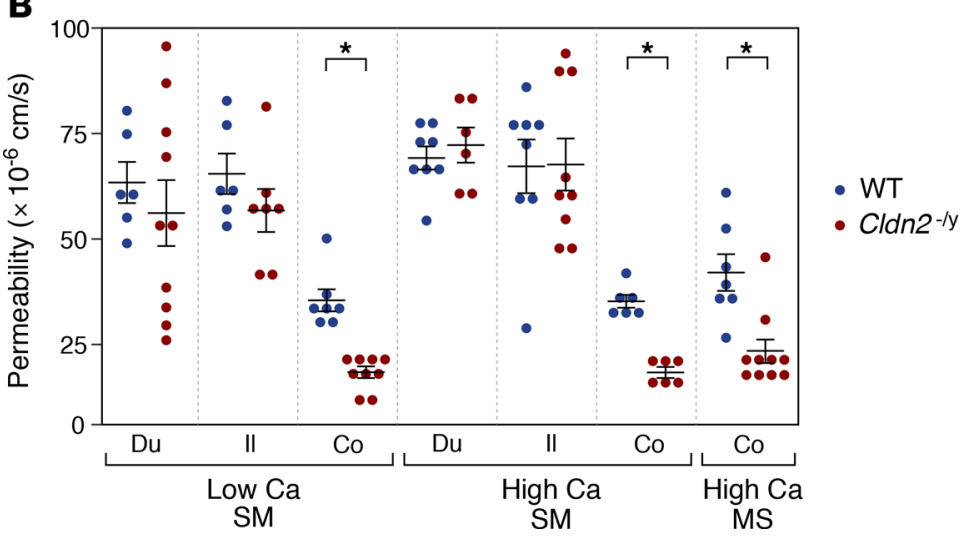

Figure 4. Everted sac assays of intestinal permeability. (A) Serosal-to-mucosal calcium flux assayed in different intestinal segments in high-calcium $(5.0 \mathrm{mM})$ solution $(n=6-8$ mice per group). (B) Summary of intestinal permeability determined in duodenum (Du), ileum (II), and colon (Co) in the presence of lowCa $(0.25 \mathrm{mM})$ or high-Ca (5.0 mM) solution. SM, serosal-to-mucosal direction; MS, mucosal-to-serosal direction ( $n=6-10$ mice per group). Fixed-factor ANOVA (independent variables: segment, calcium, direction, and genotype) showed a significant interaction of segment with genotype. Permeability was significantly lower in Cldn2 $2^{-1 y}$ compared with WT mice in the colon ${ }^{*} P=0.001$ by simple main effects analysis), but not in the duodenum or ileum.

cortex samples in GTEx was insufficient to perform eQTL analysis of kidney expression. However, we know that $C L D N 2$ has 3 alternative first exons and hence 3 alternative promoters. In the GTEx expression data, human kidney cortex and pancreas both exclusively express the same transcript (ENST00000540876.1) and therefore use the same promoter. Thus, it is highly likely that transcriptional regulation by cis-acting eQTLs in these 2 tissues is identical. Interestingly, the alleles in CLDN2 that are associated with increased risk of pancreatitis (30) are all associat-

infrequent tight junction strands (ref. 27 and Figure 7E). This suggests that the deposits originate from tubular plugs in the descending and ascending thin limbs of the loops of Henle.

Common variants in the CLDN2 gene are associated with nephrolithiasis in the general population. The phenotype of claudin-2knockout mice, with hypercalciuria due to both proximal tubular calcium wasting and increased intestinal calcium absorption, in conjunction with papillary deposition of hydroxyapatite in thin limbs of the loops of Henle, resembles the phenotype of patients with idiopathic hypercalciuria and kidney stone disease. We therefore hypothesized that genetic variants in CLDN2 might be associated with the risk of kidney stones in humans. To date, several genome-wide association studies (GWAS) of nephrolithiasis have been performed in the general population $(4,5,28)$, but none of these studies have included the $\mathrm{X}$ chromosome in their analyses. To evaluate the role of CLDN2 in human kidney stones, we examined the association of 12 single-nucleotide polymorphisms (SNPs) in the CLDN2 locus with disease risk (29). In this analysis, a total of 11,130 kidney stone cases and 187,639 controls were analyzed (Supplemental Table 5). Nine SNPs showed significant association with disease risk $(P<0.05$; Table 2$)$. There was no significant heterogeneity in the observed association between males and females (Supplemental Table 6). Three of the SNPs, rs7057398, rs12008279, and rs5917027, were previously shown to be associated with chronic pancreatitis (30).

Our hypothesis predicts that causal variants for nephrolithiasis in CLDN2 should decrease claudin-2 function or tissue expression. All 9 positive SNPs were in the noncoding region. We therefore performed an analysis for cis-acting expression quantitative trait loci (eQTLs) in CLDN2 using the data set from the GenotypeTissue Expression (GTEx) project. Seven of the SNPs associated with nephrolithiasis were genotyped in GTEx, and in all 7 cases, the nephrolithiasis risk allele was strongly associated with decreased claudin-2 expression in pancreatic tissue (to a highly statistically significant degree in 6 of the 7; Table 2). The number of kidney ed with increased claudin-2 expression in the pancreas, and with decreased risk for nephrolithiasis (Supplemental Figure 5).

Rare missense mutation in CLDN2 causes hypercalciuria and kidney stones. We recently reported a family of Iranian origin with 9 infertile men over 3 generations (31). Five of these males were diagnosed with obstructive azoospermia due to a rare missense variant in CLDN2 (p.Gly161Arg) (Supplemental Figure 6). All 5 patients had a history of kidney stones (one of which, I.7, was known to have passed a calcium stone), whereas none of the 9 unaffected adult males who participated in the study had ever had kidney stones ( $P=0.0002$ by $\chi^{2}$ test). All 5 patients were markedly hypercalciuric (Table 3), with 24-hour urine calcium excretion of $390 \pm 18 \mathrm{mg}$ (mean \pm SD; normal male $<300 \mathrm{mg}$ ). Daily urine calcium in a female carrier was $274 \mathrm{mg}$ (normal $<250 \mathrm{mg}$ ). By contrast, urine calcium excretion was normal in 2 unaffected male siblings (223 and $270 \mathrm{mg}$ ).

\section{Discussion}

In this study, we tested the hypothesis that loss of claudin-2 leads to defective PT calcium reabsorption, thereby increasing the distal delivery of calcium to the loops of Henle and predisposing mammals to nephrocalcinosis, and hence kidney stone disease. We showed that constitutive loss of claudin-2 in mice leads to hypercalciuria attributable to both a renal leak of calcium and increased net intestinal calcium absorption, the latter being due to impaired colonic calcium secretion. We identified multiple common CLDN2 SNPs that associate with modestly increased risk of kidney stone disease and are significant cis-acting eQTLs in human tissue. Finally, we identified one family with a rare missense mutation in CLDN2 that is strongly associated with both hypercalciuria and kidney stones. Our results suggest that claudin-2 plays a pathogenic role in idiopathic hypercalciuria and kidney stone disease.

PT calcium reabsorption is passive and follows sodium and water reabsorption. We and others have shown that claudin- 2 is highly expressed in the PT $(21,32)$, that it functions as a paracel- 

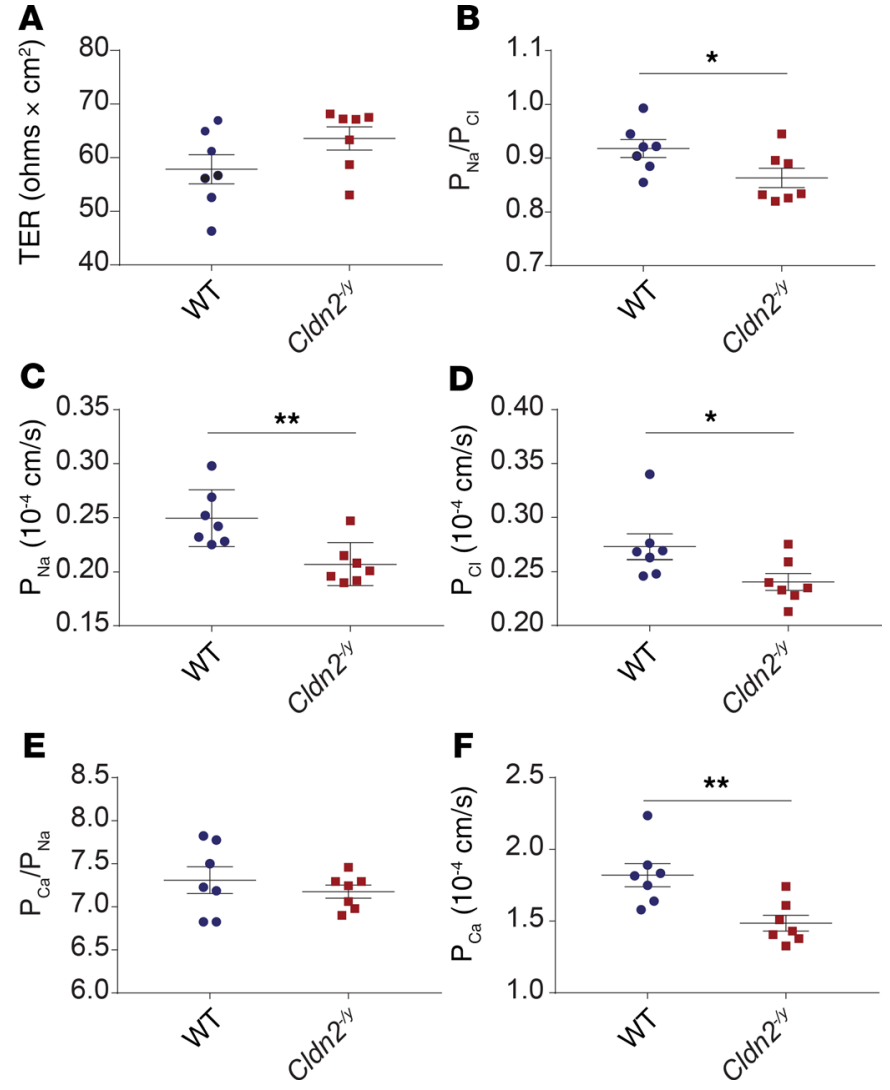

Figure 5. Ussing chamber measurements of intestinal ion permeability. Permeability properties of proximal colon tissue in WT and Cldn2-/y mice. (A) Transepithelial resistance (TER). (B-D) $P_{\mathrm{Na}} / P_{\mathrm{Cl}}(\mathbf{B}), \mathrm{P}_{\mathrm{Na}}$ (C), and $\mathrm{P}_{\mathrm{Cl}}(\mathbf{D})$ as determined from dilution potential measurement. (E and $\mathbf{F}) P_{\mathrm{Ca}} / P_{\mathrm{Na}}(\mathbf{E})$ and $P_{c_{a}}(\mathbf{F})$ as determined from bi-ionic potentials ( $n=7$ per group). Individual ion permeabilities were estimated by the method of Kimizuka and Koketsu. Bars are mean \pm SEM. ${ }^{*} P<0.05,{ }^{* *} P=0.005$ using unpaired 2 -tailed $t$ test. $P_{X}$, transepithelial permeability to $X$.

lular cation channel $(19,20,33)$, and that it is permeable to calcium as well as sodium (20). It was previously shown by Muto et al. that deletion of claudin-2 causes a reduction in $\mathrm{P}_{\mathrm{Na}}$ in PTs and an increase in $\mathrm{FECa}^{2+}$, indicating that renal tubule calcium reabsorption is decreased (22). Our work confirms that $\mathrm{Cldn}^{-/ y}$ mice have a large decrease in renal calcium reabsorption and indicates that this cannot be explained by reduced expression of calcium transporters in the distal nephron. We found that Cldn2-/y mice remain hypercalciuric, relative to WT littermates, after 5 days on a calcium-deficient diet, despite being in negative calcium balance. This suggests that Cldn2-/y mice have a primary renal calcium leak and that claudin- 2 is the mediator of paracellular calcium reabsorption in the PT. Micropuncture experiments will be needed to confirm this.

In addition, we found that $\mathrm{Cldn2}^{-/ y}$ mice have a more positive calcium balance and an exaggerated reduction in urinary calcium excretion with dietary calcium restriction. These findings were unexpected and suggest that, in addition to a reduction in renal calcium reabsorption, claudin-2 deletion also causes a primary increase in net calcium absorption in the gastrointestinal tract. The phenotype of $C l d n 2^{-/ y}$ mice resembles that of patients with idiopathic hypercalciuria that are kidney stone formers, who often exhibit both intestinal hyperabsorption of calcium and reduced renal calcium reabsorption (14).

To determine the mechanism for increased net intestinal absorption of calcium, we measured unidirectional ${ }^{45} \mathrm{Ca}$ flux in the presence of symmetrical solutions. We found no difference in fluxes in the duodenum and ileum, but a marked decrease in both serosal-mucosal and mucosal-serosal flux in the colon. This indicates that the colon has decreased passive permeability to calcium. Our findings were confirmed by measurement of permeability from equilibrium potentials in Ussing chambers, and are partially consistent with the observation by Tamura et al. that the small intestines of claudin-2-knockout animals have reduced $\mathrm{P}_{\mathrm{Na}}$ (34). Furthermore, we found no difference in active calcium absorption in the duodenum (not shown) and no difference in the expression of transcellular calcium transport proteins.

It is known that calcium transport exhibits a proximal-to-distal gradient. In the proximal small intestine, calcium is absorbed both actively (via vitamin D-dependent transcellular mechanisms) and passively, whereas in more distal segments, and particularly in the colon on a normal calcium diet, transport is predominantly passive and the net direction of flux becomes increasingly secretory. This has been demonstrated both by in vitro Ussing chamber experiments (35), and by measurements in intestinal segments perfused in vivo (36). That the electrochemical driving force for passive calcium diffusion favors secretion is explained by 2 observations: (a) The soluble fraction of total calcium in intestinal contents is surprisingly low (averaging $~ 3 \%$ ) and decreases in distal segments because of the high luminal $\mathrm{pH}(37)$; and (b) the transepithelial voltage is lumen-negative throughout the intestine and greatest in magnitude in the colon, with measured values ranging from $-20 \mathrm{mV}$ to $-60 \mathrm{mV}(38,39)$.

Thus, the preponderance of evidence suggests that normal intestinal absorption of calcium is accompanied by a continuous passive backleak of calcium into the lumen in the colon. Our findings indicate that this backleak occurs paracellularly through claudin-2 channels in the colon. In Cldn2 $2^{-/ y}$ mice, the colonic calcium permeability is decreased, and so there is greater net calcium absorption overall by the gut.

Another important similarity between $\mathrm{Cldn}^{-/ y}$ mice and recurrent kidney stone formers is the presence of calcium deposits in the renal papilla. We show that claudin-2 deletion leads to papillary nephrocalcinosis in mice. In humans, nephrocalcinosis is appreciable on CT scan in approximately one-sixth of $\mathrm{CaOx}$ stone formers and three-quarters of hydroxyapatite stone formers (40). Randall's plaques, which are papillary hydroxyapatite deposits found in the basement membranes of thin ascending limbs and the interstitium, are found in $65 \%-75 \%$ of stone formers and are a precursor to the most common stones, composed of $\mathrm{CaOx}$ (41). Twenty-five percent to $35 \%$ of stone formers have intratubular plugs of calcium, typically in the inner medullary collecting ducts and the ducts of Bellini, and these patients typically form brushite and hydroxyapatite stones (42). Plugs in the thin limb have also been observed in stone formers, most notably in patients with ileostomy, primary hyperoxaluria type I, and cystinuria (42). Interestingly, a recent study of kidneys removed for cancer suggested that tubular plugs are common even in individuals without kidney stones (43). These intratu- 


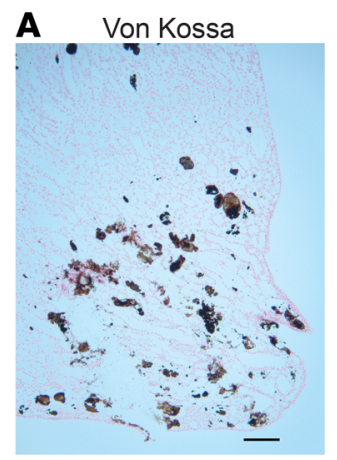

E

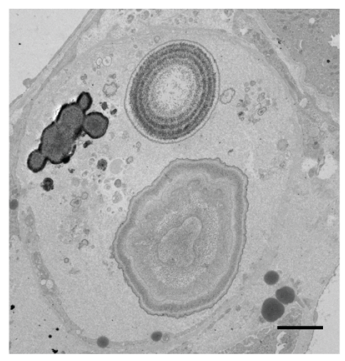

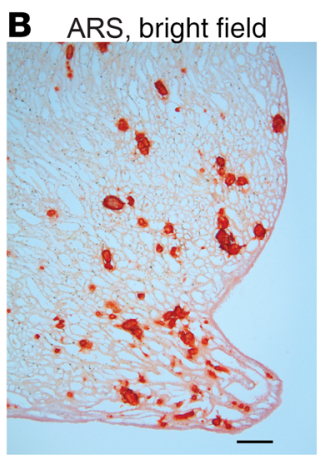

$\mathbf{F}$

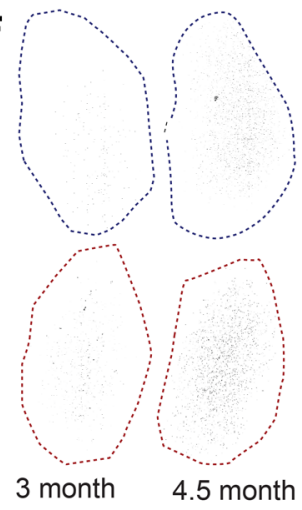

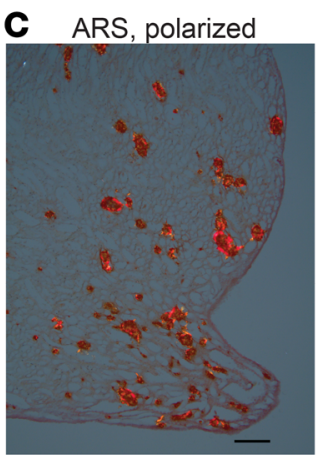

G
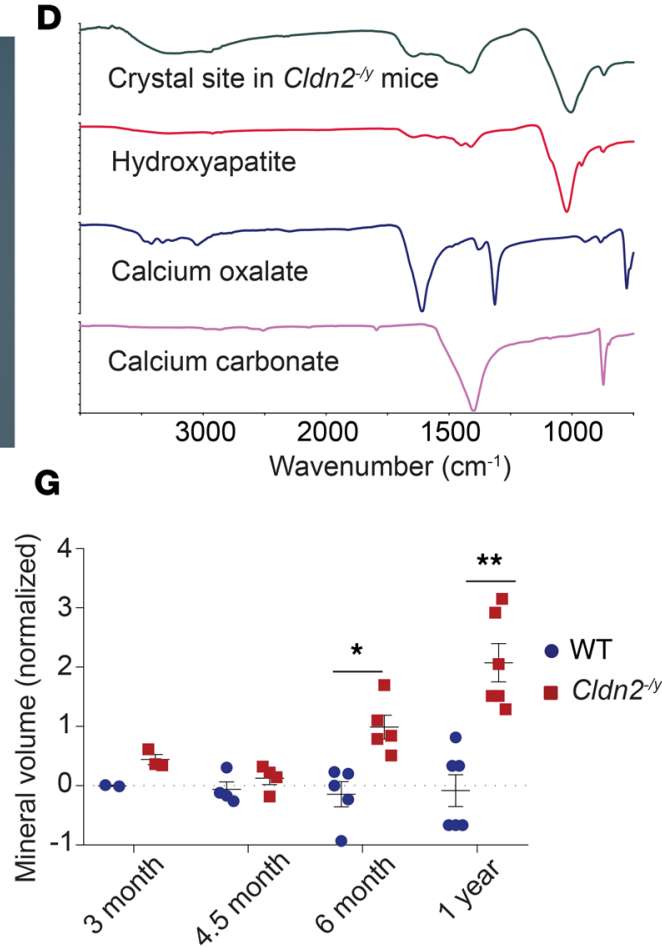

Figure 6. Calcium deposits in the papilla of $\mathbf{C l d n 2 ^ { - / y }}$ mice. (A-C) Representative kidney sections from 6-month-old Cldn2-/y mice were stained and visualized with the following methods: (A) Von Kossa. (B) Alizarin red S (ARS), pH 4.2, bright field. (C) ARS, pH 4.2, polarized light. Scale bars: $100 \mu$ m. (D) Micro-FTIR analysis shows that deposits are composed of primarily hydroxyapatite. (E) TEM reveals large-diameter aggregates of matrix and mineral with laminated deposits characteristic of hydroxyapatite. Scale bar: $2 \mu \mathrm{m}$. (F and $\mathbf{C})$ Representative 3D reconstructions of micro-CT analysis of kidneys from WT (blue outline) and Cldn2-/y (red outline) (F) and quantitation of the mineral volume in reconstruction analysis ( $n=2-5$ per group) (C). Data were normalized for each time point and log-transformed before plotting for analysis. Bars are mean \pm SEM. At each time point, differences between WT and Cldn2 ${ }^{-1 /}$ were analyzed by unpaired $t$ test and corrected for multiple comparisons using the Bonferroni-Dunn method; ${ }^{*} P<0.05,{ }^{* *} P<0.01$.

bular plugs were composed of calcium phosphate and located within AQP1-negative loops of Henle in the papilla (43), consistent with both the lowermost portions of descending thin limbs and the ascending thin limbs (44). It has been hypothesized that medullary tubule plugging might even precede and precipitate plaque formation and subsequent stone growth (45-47), though this remains unproven. The nephrocalcinosis that we observe in Cldn2-/y mice resembles the medullary plugging within the loops of Henle found in some human kidney stone patients.

Because $C l d n 2^{-/ y}$ mice and kidney stone formers with idiopathic hypercalciuria (14) have in common a defect in PT calcium reabsorption, we propose that the site of the defect uniquely predisposes to papillary nephrocalcinosis by increasing the delivery of calcium to Henle's loop. In such a scenario, reabsorption of water in the thin descending limb is predicted to increase tubular calcium and phosphate levels to the point of supersaturation by the bend of the loop (48). In addition, the medullary thick ascending limb is proposed to compensate for the PT defect by increasing reabsorption of luminal calcium, which could then enter the descending vasa recta by passive diffusion and be returned to the inner medulla and papilla (dubbed "vas washdown"), thereby generating an axial calcium gradient in the medullary interstitium $(49,50)$. This mechanism is consistent with the recent finding of preferential deposition of plaques in the basement membrane of thin ascending limbs (10), and with the predictions of a recent mathematical model (51), lending it further credence. Overall, these 2 processes could explain how defective PT calcium reabsorption causes both intratubular plugging and interstitial plaques in the papilla, and suggest that Cldn2- $2^{-y}$ mice may be a useful model for studying the complex pathogenesis of human kidney stone disease.

The similarities between $C l d n 2^{-1 / y}$ mice and kidney stone formers led us to test the hypothesis that genetic variants in the CLDN2 locus might predispose to kidney stone disease. In our population-based study, we identified 9 SNPs that are associated with nephrolithiasis, all of which are common variants. Cis-acting eQTL analysis revealed that 6 of the 7 risk variants available for analysis share a strong association with reduced claudin-2 expression in human tissue. Our findings provide strong evidence that genetic variants in the claudin-2 gene that decrease its tissue expression are causal in kidney stone disease. Unexpectedly, the non-risk alleles of several of these SNPs have been identified previously as risk alleles for alcohol-related pancreatitis and increased pancreatic claudin-2 expression. The strong reciprocal relationship between risk variants for these 2 diseases and tissue expression levels increases the likelihood that these represent true causal disease associations.

The pathogenic link between claudin-2, calcium excretion, and kidney stone disease is further corroborated by our finding of a family with a very rare missense mutation in CLDN2, in which 

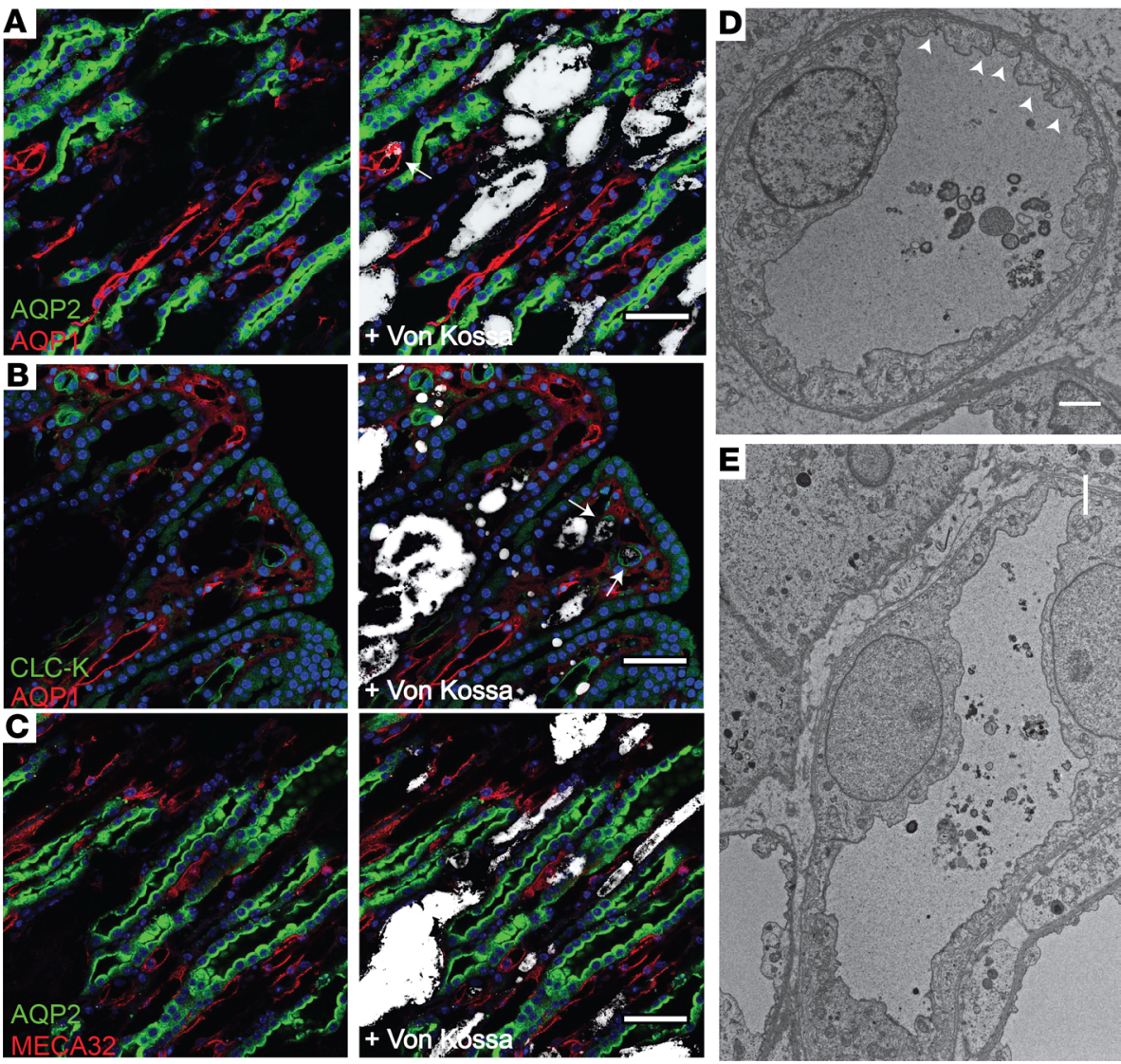

Figure 7. Nephrocalcinosis occurs within the loops of Henle of $\mathrm{Cldn2}^{-/ y}$ mice. (A-C) Confocal microscopy of papillary sections from Cldn2-/y mice shows von Kossa staining of deposits (pseudocolored white) colabeled with the following tubule markers: (A) Inner medullary collecting duct (AQP2) and thin descending limbs (AQP1). (B) Thin descending limbs (AQP1) and thin ascending limbs (CLC-K). (C) Inner medullary collecting ducts (AQP2) and vasa recta (MECA32). Association of calcium deposits with tubule markers is infrequent, but instances of colocalization with AQP1- or CLC-K-positive thin limbs are occasionally seen (arrows in A and B). Scale bars: $50 \mu \mathrm{m}$. (D and $\mathbf{E}$ ) Electron microscopy of papillae from 5-month-old Cldn2-1y mice shows small mineral deposits within type 4 thin descending limb cells with frequent tight junctions (arrowheads) (D) as well as type 3 thin ascending limb cells lacking these features (E). Scale bars: $2 \mu \mathrm{m}$. the affected males are afflicted with both hypercalciuria and kidney stone disease.

Currently, treatments for the prevention of idiopathic hypercalciuria and nephrolithiasis are limited. These patients are often treated with thiazide diuretics, which induce hypocalciuria in part by stimulating PT calcium reabsorption $(9,52)$. While affordable and relatively safe, thiazide diuretics are often contraindicated in patients because of off-target side effects. Identification of claudin-2 regulatory pathways may help to identify potential pharmacologic strategies to increase renal claudin-2 expression. We speculate that such a strategy will be effective in the prevention of kidney stones.

\section{Methods}

Animal and metabolic balance studies. Mice with global, constitutive knockout of the claudin-2 gene ( $\left.\mathrm{Cldn} 2^{\text {tmLLex/Mmcd }}\right)$ were originally generated by targeted deletion of the coding exon of Cldn 2 and backcrossed onto the C57BL/6J background, as described previously (23). Male mice were used for all experiments, except where indicated otherwise. This is due to the location of the Cldn2 gene on the X chromosome, which precludes generation of WT and knockout female littermates. Baseline measurements of urine and serum parameters were performed on 15to 17-week-old mice fed standard lab chow (Teklad Rodent Diet 8604, Envigo). Urine was collected by spontaneous voiding onto a Parafilm mat. Mice were then anesthetized with xylazine $(15 \mathrm{mg} / \mathrm{kg}$ i.p.) and ketamine $(150 \mathrm{mg} / \mathrm{kg})$, and blood was collected by cardiac puncture. To avoid possible interference of ketamine with PTH measurements, blood for this assay was collected from the submandibular vein of unanesthetized 16-week-old mice into EDTA plasma tubes. For urine and serum studies listed in Supplemental Figure 3, 17- to 26-week-old mice were used.

Metabolic balance studies were performed using mice between 14 and 18 weeks of age. Control (0.6\% calcium, TD.97191) and calcium-deficient $\left(\leq 0.01 \%\right.$ calcium $\left.^{+}, \mathrm{TD} .95027\right)$ diet was purchased in powdered form (Envigo) and prepared as a soft agar diet using 1\% Difco Noble agar (BD Biosciences) in a ratio of 5:8 wt/vol diet to water. Mice were first acclimated in metabolic cages (MMC100, Hatteras Instruments) for 48 hours with free access to food and water. Control diet was started at this time (day -4). At day -2 , mice were returned to conventional housing for 2 days of recovery. At day 0 , mice were returned to metabolic cages for collection of urine and feces. Food weight, water weight, and urine volume were recorded each day, and mice were removed for approximately 10 minutes each day during collection of urine, feces, and cleaning of cages. At day 5 , a subset of mice was switched to the low-calcium diet. At the completion of the study, serum was collected by cardiac exsanguination.

Serum, urine, and fecal analysis. Urine was collected in 2 separate tubes. $\mathrm{HCl}$ (final $0.3 \mathrm{~N}$ ) was added to 1 aliquot for calcium determination. Both aliquots were then centrifuged at $5000 \mathrm{~g}$ for 1 minute and the supernatant collected. Feces were collected in glass vials, and calcium was extracted by wet ashing. Briefly, 2:1 nitric/perchloric acid was added to each sample $(3 \mathrm{~mL}$ total $)$ and heated at $95^{\circ} \mathrm{C}$ until dissolved completely ( $\sim 7$ hours), then serially diluted to a total volume of $400 \mathrm{~mL}$. Serum, urine, and fecal calcium was measured by a colorimetric assay (Quantichrom, BioAssay Systems). Urine creatinine was measured by the Jaffe reaction (Cayman Chemical). Serum creatinine (Cr) was measured by the University of Texas Southwestern Medical 
Table 2. CLDN2 gene variants associated with nephrolithiasis

\begin{tabular}{|c|c|c|c|c|c|c|c|c|}
\hline \multirow{2}{*}{ Reference SNP ID } & \multirow[t]{2}{*}{ Position } & \multirow[t]{2}{*}{ Major allele } & \multirow[t]{2}{*}{ Minor allele } & \multirow[t]{2}{*}{ MAF } & \multicolumn{2}{|c|}{ METAL } & \multicolumn{2}{|c|}{ GTEx } \\
\hline & & & & & $\mathrm{OR}$ & $P$ value & NES & $P$ value \\
\hline rs7057398 & Intron & $\mathrm{T}$ & C & 0.4848 & 1.029 & 0.0152 & -0.48 & $1.7 \times 10^{-15}$ \\
\hline rs55662019 & Intron & $A$ & $\mathrm{~T}$ & 0.1099 & 0.917 & 0.0113 & 0.13 & 0.059 \\
\hline rs12837024 & Intron & C & $\mathrm{T}$ & 0.231 & 1.0303 & 0.0200 & -0.45 & $2.8 \times 10^{-12}$ \\
\hline rs73247968 & Intron & C & $A$ & 0.1465 & 1.035 & 0.0462 & -0.44 & $1.2 \times 10^{-8}$ \\
\hline rs12008279 & Intron & $G$ & A & 0.3698 & 0.915 & 0.0085 & 0.15 & $5.7 \times 10^{-3}$ \\
\hline rs5917027 & Intron & $C$ & $\mathrm{~T}$ & 0.2477 & 0.925 & 0.0055 & 0.26 & $2.4 \times 10^{-6}$ \\
\hline rs6523906 & Intron & A & G & 0.3746 & 0.925 & 0.0055 & 0.21 & $1.0 \times 10^{-4}$ \\
\hline rs6622121 & Intron & $\mathrm{T}$ & $C$ & 0.3828 & 0.926 & 0.0057 & & \\
\hline rs147829672 & 3'-UTR & C & A & 0.014 & 0.927 & 0.0080 & & \\
\hline
\end{tabular}

MAF, minor allele frequency (1000 Genomes project). OR, odds ratio for nephrolithiasis with minor allele as the reference allele. When major allele is associated with disease risk, $\mathrm{OR}$ is $>1$. METAL $P$ value, $P$ value for association of variants with nephrolithiasis by meta-analysis of 2 independent $\mathrm{GWAS}$ cohorts. NES, normalized effect size of the eQTL in GTEx, defined as the slope of the linear regression between genotype and expression (effect of the risk allele relative to the alternative allele). Negative values indicate that the major allele is associated with decreased tissue expression in pancreas. GTEx $P$ value, $P$ value for the test of the hypothesis that the slope of the linear regression between genotype and expression deviates from 0 . Blue text indicates those loci where the major allele is associated with increased risk of nephrolithiasis (OR $>1.0$ ) and with decreased tissue expression (NES $<0$ ); red text indicates loci where the major allele is associated with decreased risk of nephrolithiasis and with increased tissue expression.

Center O’Brien Center Kidney Physiology Core by capillary electrophoresis. $\mathrm{FECa}^{2+}$ was calculated as

$$
\text { (urine } \left.\mathrm{Ca}^{2+} \times \text { serum } \mathrm{Cr}\right) /\left(0.5 \times \text { serum } \mathrm{Ca}^{2+} \times \text { urine } \mathrm{Cr}\right)
$$

\section{(Equation 1)}

A correction factor of 0.5 was used to estimate the ionized fraction of serum calcium (53). Plasma intact PTH (Immutopics Mouse Intact PTH 1-84) and 1,25-dihydroxyvitamin D (Immunodiagnostic Systems) were measured by ELISA. Urine was also assayed for oxalate (EnzyChrom, BioAssay Systems), citrate (EnzyChrom, BioAssay Systems), magnesium (QuantiChrom, BioAssay Systems), and inorganic phosphorus (Pointe Scientific).

Quantitative reverse transcription PCR. Whole tissue RNA was extracted with TRI Reagent (Sigma-Aldrich). First-strand cDNA iScript Reverse Transcription Supermix for quantitative reverse transcription PCR (RT-qPCR) (Bio-Rad) was used for first-strand cDNA synthesis. For kidney and duodenal tissue, a CFX96 Touch Real-Time PCR Detection System and iTaq Universal SYBR Green Supermix (Bio-Rad) were used for quantitative PCR using the primers listed in Supplemental Table 7. mRNA quantitation of proximal colon, ileum, and jejunum was performed by TaqMan assay using the ABI Prism 7900 HT Sequence Detection System (Applied Biosystems) and primer sequences previously reported (54). Expression levels were normalized to 1 of 3 housekeeping genes, $\beta$-actin, ezrin, or GAPDH.

Immunoblotting. Kidney tissue was minced with a razor blade and collected in protein isolation buffer composed of $20 \mathrm{mM}$ HEPES $(\mathrm{pH}$ 7.4), $10 \mathrm{mM} \mathrm{KCl}, 2 \mathrm{mM} \mathrm{MgCl}, 1 \mathrm{mM}$ EDTA, and $1 \mathrm{mM}$ EGTA with protease inhibitors (cOmplete Mini, Roche Diagnostics). Each sample was homogenized for 15 -second increments every minute for 5 minutes at a low-speed setting with an Ultra-Turrax T25 (IKA-Labortechnik) and then centrifuged at $1800 \mathrm{~g}$ for 10 minutes. Lysates were heated at $95^{\circ} \mathrm{C}$ for 10 minutes in reducing SDS-PAGE buffer and loaded into a polyacrylamide gel. Protein was then transferred to a PVDF membrane and blocked using 5\% nonfat dry milk. Primary antibody incubation was performed overnight at $4^{\circ} \mathrm{C}$ using the following antibodies: mouse anti-calbindin-D28k (1:1000; Swant 300), mouse anti-claudin-2 (1:500; Thermo Fisher Scientific 32-5600), and mouse anti- $\beta$-actin (1:1000; Sigma-Aldrich A2066). HRP-conjugated secondary antibodies were incubated at a concentration of 1:5000 (GE Healthcare Bio-Sciences) and bands detected using chemiluminescence (Pierce). Quantitation of densitometry was achieved using Image (NIH) and normalized to $\beta$-actin.

Histological analysis. Six-month-old mice fed standard lab chow were anesthetized using ketamine and xylazine, and cardiac perfusion fixation was performed using $4 \%$ paraformaldehyde (PFA) in PBS. Kidneys were postfixed in $4 \%$ PFA for 4 hours at room temperature. Initial calcium staining was performed on paraffin-embedded sections that were deparaffinized and rehydrated. For von Kossa staining, sections were incubated in $5 \%$ aqueous silver nitrate for 1 hour under UV light, and $5 \%$ sodium thiosulfate for 1 minute. For alizarin red S staining, tissues were placed in $2 \%$ alizarin red S ( $\mathrm{pH} 4.3$ ) for 1-3 minutes.

Immunofluorescence was performed on frozen sections. Fixed kidneys were cryoprotected in sucrose and embedded in OCT compound, and $5-\mu \mathrm{m}$ sections were cut. Slides were first stained using the von Kossa technique. Antigen retrieval was then performed with 10 $\mathrm{mM}$ sodium citrate in a steamer for 6 minutes. Aldehyde quenching was accomplished by incubating in $0.3 \mathrm{M}$ glycine in PBS; then slides were blocked for 1 hour in PBS with 5\% normal goat serum, 1\% BSA, and $0.3 \%$ Triton $\mathrm{X}-100$. The primary antibodies used were CLC-K (1:200; Alomone Labs ACL-004), AQP1 (1:500; Abcam ab9566), AQP2 (1:500; a gift from Mark Knepper, National Heart, Lung, and Blood Institute, Bethesda, Maryland, USA), MECA32 (1:100; Developmental Studies Hybridoma Bank, University of Iowa, Iowa City, Iowa, USA). Lipofuscin was quenched with 0.1\% Sudan Black B in $70 \%$ ethanol for 15 minutes, before application of secondary antibodies (Alexa Fluor 488- and 555-conjugated goat anti-rabbit and anti-mouse IgG, 1:1000; Thermo Fisher Scientific). Confocal fluorescent images were captured along with bright-field images for von Kossa stain (Leica TCS 
Table 3. Urine calcium and kidney stone disease in a family with X-linked obstructive azoospermia due to CLDN2 mutations

\begin{tabular}{|c|c|c|c|c|c|c|c|}
\hline Subject ID ${ }^{A}$ & Age when studied & Sex & CLDN2 mutation & Male infertility & $\begin{array}{l}\text { Urine total volume } \\
\quad(\mathrm{mL} / 24 \mathrm{~h})\end{array}$ & $\begin{array}{l}\text { Urine calcium } \\
(\mathrm{mg} / 24 \mathrm{~h})\end{array}$ & Kidney stones \\
\hline 1.5 & 60 & M & G161R & $Y$ & 1300 & 364 & $Y$ \\
\hline 1.8 & 50 & M & None & $\mathrm{N}$ & 1700 & 270 & $\mathrm{~N}$ \\
\hline 1.9 & 49 & M & None & $\mathrm{N}$ & - & - & $\mathrm{N}$ \\
\hline I.10 & 65 & $\mathrm{~F}$ & G161R carrier & NA & 700 & 274 & $Y$ \\
\hline II.13 & 40 & M & None & $\mathrm{N}$ & - & - & $\mathrm{N}$ \\
\hline II. 27 & 52 & M & G161R & $Y$ & 1050 & 415 & $Y$ \\
\hline II.30 & 49 & M & G161R & $Y$ & 1200 & 405 & $Y$ \\
\hline II.31 & 51 & M & None & $\mathrm{N}$ & 900 & 223 & $\mathrm{~N}$ \\
\hline II.35 & 68 & M & None & $\mathrm{N}$ & - & - & $\mathrm{N}$ \\
\hline III.19 & 28 & M & None & $\mathrm{N}$ & - & - & $\mathrm{N}$ \\
\hline
\end{tabular}

Ancludes all affected patients and unaffected family members who had ascertainment of kidney stone history. Subject ID is generation-individual number (please refer to pedigree chart in Supplemental Figure 6).

SPE microscope). Von Kossa images were pseudocolored, then overlaid onto the fluorescent images using Image $(\mathrm{NIH})$.

Micro-CT analysis of kidneys. Kidneys from 6-month-old mice were fixed and ethanol-dehydrated and then scanned with a highresolution micro-CT scanner ( $\mu \mathrm{CT} 40$, Scanco Medical) as previously described (55). Data were acquired at $55 \mathrm{keV}$ and $6 \mu \mathrm{m}$ cubic resolutions. Renal calcifications were assessed with a threshold of 220.

Bone measurements. Dual-energy x-ray absorptiometry (DEXA; Lunar PIXImus, GE Medical Systems) was used to measure bone mineral density in anesthetized mice $(0.25 \times$ ketamine/xylazine cocktail) at $4.7,6,8$, and 10 weeks of age. Two different sites were determined by adjustment of the region of interest: femur and lumbar vertebrae. Some animals were fed a pelleted calcium-deficient diet (TD.95027, Envigo) at 12 weeks of age for 4 weeks. During the low-calcium diet, measurements were taken at $12,13,14,15$, and 16 weeks of age. MicroCT analysis was performed on femurs from 10-week-old animals as described previously (55).

Transmission electron microscopy. Renal papillae were dissected from fresh kidneys, fixed in 3\% glutaraldehyde in $0.1 \mathrm{M}$ cacodylate buffer, and postfixed in $1 \%$ osmium tetroxide in $0.1 \mathrm{M}$ cacodylate buffer for 1 hour. They were then dehydrated in ethanol and propylene oxide and embedded in EMbed 812 resin (Electron Microscopy Sciences). Cross sections were cut through the papilla block at $80 \mathrm{~nm}$ thickness and picked up on 250-mesh copper grids. Next, blocks were sectioned $10 \mu \mathrm{m}$ deeper, and the same sectioning process was repeated twice. These thin sections were then contrasted with 3\% uranyl acetate aqueous and Sato's lead stain. Grids were viewed at $100 \mathrm{kV}$ in a JEOL JEM 1400 transmission electron microscope, and images were captured as TIFF files with an AMT camera.

Micro-Fourier transform infrared spectroscopy. Kidney sections ( $~ 5$ $\mu \mathrm{m})$ were mounted on low-E glass slides (Kevley Technologies) for attenuated total internal reflection (ATR) imaging analysis. A serial section stained with Yasue silver replacement was used as a control section. Before infrared analysis, the control was visually examined with an Olympus white light microscope ( $\times 20$ objective) to determine the areas of interest. Sections for ATR-FTIR imaging were not stained. ATR infrared images were collected with a PerkinElmer Spectrum Spotlight 400 infrared imaging microscope interfaced to a PerkinElmer FTIR spectrometer, as described previously (11). Each image $(400 \times 400 \mu \mathrm{m}$ area $)$ had a spatial resolution of $1.56 \mu \mathrm{m} /$ pixel and contained 65,746 infrared spectra collected at a spectral resolution of 8 wavenumbers. Each spectrum in the image is the average of 4 individual scans. The images were further processed using Spectrum Image software (PerkinElmer).

Everted gut sac assays. Ex vivo everted intestinal sac assays were performed by a modification of previously published methods $(56,57)$. Intestinal segments from the duodenum (defined as the first $4 \mathrm{~cm}$ of small intestine), ileum, and colon were excised, perfused with PBS to remove any fecal matter, and everted over a wetted glass rod. They were then filled with $0.4 \mathrm{~mL}$ of solution (serosal side) and ligated at both ends so that the final length of the sealed sac was approximately 6 $\mathrm{cm}$. Sacs were placed in individual Erlenmeyer flasks and bathed with $5 \mathrm{~mL}$ of solution (mucosal side) continuously bubbled with $100 \% \mathrm{O}_{2}$, and stirred by vigorous shaking in a $37^{\circ} \mathrm{C}$ water bath. The composition of both serosal and mucosal solutions was identical and consisted of $125 \mathrm{mM} \mathrm{NaCl}, 10 \mathrm{mM}$ fructose, $30 \mathrm{mM}$ Tris- $\mathrm{Cl}$ (pH 7.4), and either $0.25 \mathrm{mM} \mathrm{CaCl}_{2}$ (low calcium) or $5.0 \mathrm{mM} \mathrm{CaCl}_{2}$ (high calcium). For unidirectional tracer flux studies, ${ }^{45} \mathrm{CaCl}_{2}$ was added to a final activity of $16.7 \mu \mathrm{Ci} / \mathrm{L}$ to the solution on one side (cis). For serosal-to-mucosal flux assays, ${ }^{45} \mathrm{CaCl}_{2}$ was included in the serosal solution at a final activity of $16.7 \mu \mathrm{Ci} / \mathrm{L}$. Samples were collected from the mucosal solution at 30-minute intervals up to 90 minutes, for liquid scintillation counting. For mucosal-to-serosal flux assays, ${ }^{45} \mathrm{CaCl}_{2}$ was included in the mucosal solution at the same final activity as above. After 60 minutes, the 
sac was taken out, washed briefly by submerging twice in $150 \mathrm{~mL}$ of ice-cold solution, and blotted dry, and its contents emptied and sampled for scintillation counting. In each case, the transepithelial flux and permeability were determined from the initial rate of ${ }^{45} \mathrm{Ca}$ accumulation in the trans compartment.

Ussing chamber permeability assays. Proximal colon $(1.2 \mathrm{~cm}$ distal to the ileocecal junction) was excised from claudin-2-knockout mice and WT littermates (9-13 weeks old) and linearized. Whole-thickness preparations were initially used. To test the contribution of the seromuscular layer, unstripped preparations were compared with preparations in which the seromusculature was visualized with a dissecting microscope (Olympus SZ60, Olympus America) and gently stripped away with a pair of fine forceps. The colon segments were then mounted in P2407B sliders (1.2-mm-diameter circular aperture) and placed into P2400 Ussing chambers connected to a VCC Multichannel Voltage/Current Clamp (Physiologic Instruments). Both hemichambers were filled with $4 \mathrm{~mL}$ modified Krebs-Ringer buffer ("control" buffer) $\left(144 \mathrm{mM} \mathrm{Na}^{+}, 3.6 \mathrm{mM} \mathrm{K}^{+}, 146 \mathrm{mM} \mathrm{Cl}^{-}, 1 \mathrm{mM} \mathrm{Mg}^{2+}, 1.3 \mathrm{mM} \mathrm{Ca}\right.$ gluconate, $2 \mathrm{mM} \mathrm{PO}_{4}^{-}, \mathrm{pH} 7.4$ ) at $37^{\circ} \mathrm{C}$ and bubbled with $5 \% \mathrm{CO}_{2}$ (balance $\mathrm{O}_{2}$ ). After 15 minutes, a $90-\mu \mathrm{A}$ current was pulsed across the tissue 3 times for 4 seconds, and the resulting voltage was used to determine transepithelial resistance by Ohm's law. The apical solution was then changed to a low- $\mathrm{NaCl}$ solution $\left(30 \mathrm{mM} \mathrm{Na}^{+}, 3.6 \mathrm{mM} \mathrm{K}^{+}, 32 \mathrm{mM} \mathrm{Cl}^{-}\right.$, $1 \mathrm{mM} \mathrm{Mg}^{2+}, 1.3 \mathrm{mM}$ Ca gluconate, $2 \mathrm{mM}$ PO4-, $227 \mathrm{mM}$ mannitol, $\mathrm{pH}$ 7.4). The resulting peak change in transepithelial voltage was used to determine the permeability ratio of $\mathrm{Na}^{+}$to $\mathrm{Cl}^{-}\left(\mathrm{P}_{\mathrm{Na}} / \mathrm{P}_{\mathrm{Cl}}\right)$ and absolute permeability to $\mathrm{Na}^{+}$using the Goldman-Hodgkin-Katz and simplified Kimizuka-Koketsu equations $(58,59)$. The apical buffer was then exchanged for the control buffer. When the voltage stabilized, transepithelial resistance was determined as above. Bi-ionic diffusion potential was then used to assess permeability to calcium $\left(\mathrm{P}_{\mathrm{Ca}}\right)$ by exchanging the basolateral buffer $\left(140 \mathrm{mM} \mathrm{Na}^{+}, 3.6 \mathrm{mM} \mathrm{K}{ }^{+}, 146\right.$ $\mathrm{mM} \mathrm{Cl}^{-}, 1 \mathrm{mM} \mathrm{Mg}{ }^{2+}, 1.3 \mathrm{mM}$ Ca gluconate, $5 \mathrm{mM}$ mannitol, $\mathrm{pH}$ 7.4) and apical buffer $\left(3.6 \mathrm{mM} \mathrm{K}^{+}, 146 \mathrm{mM} \mathrm{Cl}^{-}, 1 \mathrm{mM} \mathrm{Mg}^{2+}, 70 \mathrm{mM} \mathrm{Ca}^{2+}\right.$, $3 \mathrm{mM}$ HEPES, pH 7.4) simultaneously and recording peak change in transepithelial voltage. Both buffers were then exchanged for the control buffers, and transepithelial resistance was determined as above when voltage stabilized. A change in resistance of no more than $25 \%$ was used to determine tissue viability (54). To further test tissue viability, forskolin $(0.1 \mu \mathrm{M})$ was applied to both chambers and a potential difference measured. All samples included for analysis demonstrated a decrease of at least $50 \%$. All changes in potential were corrected for liquid junction potentials as previously described (20). All basolateral buffers contained $10 \mathrm{mM}$ dextrose and $100 \mu \mathrm{M}$ ouabain to block transcellular $\mathrm{Na}^{+}$transport, and all apical solutions contained $10 \mathrm{mM}$ mannitol to balance osmolarity and $100 \mu \mathrm{M}$ ruthenium red to block transcellular calcium transport via TRPV6. Osmolarity of buffers measured 291 \pm 1 mOsm using an Advanced Instruments Model 3D3 osmometer.

Human DNA sample genotyping and population-based gene association analysis. The characteristics of the study populations are shown in Supplemental Table 5. DNA samples of 6246 kidney stone cases (study 1), 4884 kidney stone cases (study 2), and 158,772 non-kidney stone controls (study 2) were obtained from Biobank Japan (60, 61); 28,867 controls (study 1) were from 3 population-based cohorts, including the Japan Public Health Center-based Prospective Study (JPHC Study) (62), the Japan Multi-Institutional Collaborative Cohort Study (J-MICC Study) (63), and the Tohoku Medical Megabank Organization (ToMMo)
$(64,65)$. These samples were genotyped in previous studies by our collaborators $(29,66,67)$. Genomic DNA samples were extracted from peripheral blood leukocytes and normal tissues using a standard method. All participants provided written, informed consent, and the ethical committees at each institute approved the project. All samples were genotyped by Illumina OmniExpress Exome or the OmniExpress+ HumanExome BeadChip (Supplemental Table 5).

SNPs were excluded if they met the following criteria: MAF < 0.005 ; Hardy-Weinberg equilibrium $P$ value $<1 \times 10^{-6}$; call rate $=0$ (study 1) or $<0.01$ (study 2). Imputation of the ungenotyped SNPs was conducted by $\mathrm{MaCH}$ (68) and minimac (69) using the data from the Japanese in Tokyo (JPT), Han Chinese in South, China (CHS), and Chinese in Denver, Colorado, USA (CHD) and using the 1000 Genomes project phase 1 (release 16, March 2012) as a reference. We excluded SNPs with a large allele frequency difference between the reference panel and the GWAS (>0.16) as described previously (70). We also excluded SNPs with low imputation quality score $(\mathrm{Rsq}<0.3)$ and insertion/deletion polymorphisms. Finally, we selected 12 SNPs within CLDN2 loci for association analysis. Association of these SNPs with kidney stone risk was assessed by logistic regression. Covariates used in each study were age and principal components 1-10 (71).

For each study, we stratified samples into male and female groups, and analyzed the association of SNPs with kidney stone risk separately, then conducted a meta-analysis of the combined male and female data using METAL (72). The effect of allelic dosage was modeled as 0 or 2 in males and 0,1 , or 2 in females (i.e., dosage compensation for $\mathrm{X}$ inactivation). A meta-analysis of study 1 and study 2 was then conducted. Heterogeneity across each pair of studies was examined using Cochran's Q test (73).

Cis $e Q T L$ analysis. SNPs associated with kidney stone risk were queried to identify cis-acting eQTLs. Analysis was performed with FastQTL using Release V7 of the Genotype-Tissue Expression (GTEx) project data set (74) (https://gtexportal.org/; accessed February 16, 2018). Nominal $P$ values were generated for each CLDN2 gene variant by testing of the alternative hypothesis that the slope of a linear regression model between genotype and claudin-2 expression, in pancreas samples from 220 individuals, deviates from 0 . The normalized effect size of the eQTLs, defined as the slope of the linear regression, was computed in a normalized space, so its magnitude has no direct biological interpretation.

Family-based genetic study. A family of Iranian origin with obstructive azoospermia, which has previously been reported (31), was enrolled at the Infertility Clinic \& Reproductive Biomedicine Research Center of Royan Institute, Tehran, Iran. A history was obtained from all participants to ascertain prior kidney stone events, and 24-hour urine collections were obtained from selected individuals to determine urinary calcium excretion. The genotypes of family members for the CLDN2 missense variant, c.481G>C (p.Gly161Arg), determined by Sanger sequencing, were previously reported (31).

Statistics. Statistical analyses for the mouse studies were performed with GraphPad Prism 8 software. Data are expressed as mean \pm SEM. Student's 2-tailed $t$ test was used to test differences between means in 2-group comparisons. ANOVA was used to test for differences in multigroup experiments. $P$ values less than 0.05 were considered significant.

Study approval. All animal experiments were performed in accordance with NIH guidelines on the use of laboratory animals and were approved by the Institutional Animal Care and Use Committee at 
the University of Kansas Medical Center or the University of Alberta animal ethics committee, Health Sciences Section. For the genetic studies, the study protocols conformed to the Declaration of Helsinki, and all human subjects provided written informed consent. The population-based genome association study was approved by the ethical committee at the University of Tokyo. The family-based genetic study was approved by the Institutional Review Board of the Royan Institute Research Center and the Royan Ethics Committee, Tehran, Iran.

\section{Author contributions}

JNC and ASLY designed the overall study and drafted the manuscript. JNC, MS, LP, and MBF conducted the main set of mouse experiments. MRB and RTA conducted the Ussing chamber studies. AJS conducted the micro-FTIR analysis. PSNR assisted with micro-CT and DEXA experimental design and analysis. TF assisted with interpretation of the histological studies. APE assisted in the analysis and interpretation of nephrocalcinosis data. KM, YK, and CT designed and conducted the genome association data analysis. MA and MT performed the family genetic study. All authors reviewed and edited the manuscript and approved the final draft.

\section{Acknowledgments}

We acknowledge Barbara Fegley for her assistance in the preparation of renal papillae for transmission electron microscopy. We thank Rajiv Kumar, Mayo Clinic, Rochester, for his guidance in establishing the everted gut assays. This work was supported by NIH grants R01 DK062283 and P20 GM130423 (to ASLY), F30 DK109605 (to JNC), P01 DK56788 (to APE), and Natural Sciences and Engineering Research Council of Canada Discovery Grant RGPIN 05842 (to RTA). The Genotype-Tissue Expression (GTEx) project is supported by the NIH Common Fund and by NCI, NHGRI, NHLBI, NIDA, $\mathrm{NIMH}$, and NINDS. The University of Kansas Medical Center Electron Microscope Research Laboratory and Confocal Imaging Core are supported, in part, by NIH grant P20 GM104936. The University of Texas Southwestern O'Brien Kidney Center Research Core is funded by NIH grant P30 DK079238.

Address correspondence to: Alan S.L. Yu, Division of Nephrology and Hypertension and the Jared Grantham Kidney Institute, 3901 Rainbow Boulevard, Kansas City, Kansas 66103, USA. Email: ayu@kumc.edu.
1. Scales CD, Smith AC, Hanley JM, Saigal CS, Urologic Diseases in America Project. Prevalence of kidney stones in the United States. Eur Urol. 2012;62(1):160-165.

2. Resnick M, Pridgen DB, Goodman HO. Genetic predisposition to formation of calcium oxalate renal calculi. NEngl JMed.1968;278(24):1313-1318.

3. Goldfarb DS, Fischer ME, Keich Y, Goldberg J. A twin study of genetic and dietary influences on nephrolithiasis: a report from the Vietnam Era Twin (VET) Registry. Kidney Int. 2005;67(3):1053-1061.

4. Urabe Y, et al. A genome-wide association study of nephrolithiasis in the Japanese population identifies novel susceptible loci at 5q35.3, 7p14.3, and 13q14.1. PLoS Genet. 2012;8(3):e1002541.

5 . Thorleifsson G, et al. Sequence variants in the CLDN14 gene associate with kidney stones and bone mineral density. Nat Genet. 2009;41(8):926-930.

6. Gudbjartsson DF, et al. Association of variants at UMOD with chronic kidney disease and kidney stones-role of age and comorbid diseases. PLoS Genet. 2010;6(7):e1001039.

7. Walker V, Stansbridge EM, Griffin DG. Demography and biochemistry of 2800 patients from a renal stones clinic. Ann Clin Biochem. 2013;50 (pt 2):127-139.

8. Evan AP, et al. Contrasting histopathology and crystal deposits in kidneys of idiopathic stone formers who produce hydroxy apatite, brushite, or calcium oxalate stones. Anat Rec (Hoboken). 2014;297(4):731-748.

9. Worcester EM, Coe FL. Clinical practice. Calcium kidney stones. $N$ Engl J Med. 2010;363(10):954-963.

10. Evan AP, Coe FL, Lingeman J, Bledsoe S, Worcester EM. Randall's plaque in stone formers originates in ascending thin limbs. Am J Physiol Renal Physiol. 2018;315(5):F1236-F1242.

11. Evan AP, et al. Randall's plaque of patients with nephrolithiasis begins in basement mem- branes of thin loops of Henle. J Clin Invest. 2003;111(5):607-616.

12. Moe OW. Kidney stones: pathophysiology and medical management. Lancet 2006;367(9507):333-344

13. Sutton RA, Walker VR. Responses to hydrochlorothiazide and acetazolamide in patients with calcium stones. Evidence suggesting a defect in renal tubular function. $N$ Engl J Med 1980;302(13):709-713.

14. Worcester EM, et al. Evidence for increased postprandial distal nephron calcium delivery in hypercalciuric stone-forming patients. Am J Physiol Renal Physiol. 2008;295(5):F1286-F1294.

15. Suki WN. Calcium transport in the nephron. Am Physiol. 1979;237(1):F1-F6.

16. Ng RC, Rouse D, Suki WN. Calcium transport in the rabbit superficial proximal convoluted tubule. J Clin Invest. 1984;74(3):834-842.

17. Hou J, Rajagopal M, Yu AS. Claudins and the kidney. Annu Rev Physiol. 2013;75:479-501.

18. Furuse M, Furuse K, Sasaki H, Tsukita S. Conversion of zonulae occludentes from tight to leaky strand type by introducing claudin-2 into Madin-Darby canine kidney I cells. JCell Biol. 2001;153(2):263-272.

19. Amasheh S, et al. Claudin-2 expression induces cation-selective channels in tight junctions of epithelial cells. JCell Sci. 2002;115(pt 24):4969-4976.

20. Yu AS, et al. Molecular basis for cation selectivity in claudin-2-based paracellular pores: identification of an electrostatic interaction site. JGen Physiol. 2009;133(1):111-127.

21. Enck AH, Berger UV, Yu AS. Claudin-2 is selectively expressed in proximal nephron in mouse kidney. Am J Physiol Renal Physiol. 2001;281(5):F966-F974.

22. Muto S, et al. Claudin-2-deficient mice are defective in the leaky and cation-selective paracellular permeability properties of renal proximal tubules. Proc Natl Acad Sci US A. 2010;107(17):8011-8016.
23. Pei L, et al. Paracellular epithelial sodium transport maximizes energy efficiency in the kidney. J Clin Invest. 2016;126(7):2509-2518.

24. Hoenderop JG, Nilius B, Bindels RJ. Calcium absorption across epithelia. Physiol Rev. 2005;85(1):373-422.

25. Kim M, Sessler NE, Tembe V, Favus MJ, Bushinsky DA. Response of genetic hypercalciuric rats to a low calcium diet. Kidney Int . 1993;43(1):189-196.

26. Proia AD, Brinn NT. Identification of calcium oxalate crystals using alizarin red S stain. Arch Pathol Lab Med.1985;109(2):186-189.

27. Pannabecker TL. Structure and function of the thin limbs of the loop of Henle. Compr Physiol. 2012;2(3):2063-2086.

28. Oddsson A, et al. Common and rare variants associated with kidney stones and biochemical traits. Nat Commun. 2015;6:7975.

29. Tanikawa C, et al. GWAS identifies nine nephrolithiasis susceptibility loci related with metabolic and crystallization pathways. bioRxiv. 2019. https://doi.org/10.1101/519553.

30. Whitcomb DC, et al. Common genetic variants in the CLDN2 and PRSS1-PRSS2 loci alter risk for alcohol-related and sporadic pancreatitis. Nat Genet. 2012;44(12):1349-1354.

31. Askari M, et al. Identification of a missense variant in CLDN2 in obstructive azoospermia. J Hum Genet. 2019;64(10):1023-1032.

32. Kiuchi-Saishin Y, Gotoh S, Furuse M, Takasuga A, Tano Y, Tsukita S. Differential expression patterns of claudins, tight junction membrane proteins, in mouse nephron segments. J Am Soc Nephrol.2002;13(4):875-886.

33. Weber CR, et al. Claudin-2-dependent paracellular channels are dynamically gated. Elife. 2015;4:e09906.

34. Tamura A, et al. Loss of claudin-15, but not claudin-2, causes $\mathrm{Na}^{+}$deficiency and glucose malabsorption in mouse small intestine. Gastroenterology. 2011;140(3):913-923.

35. Karbach U, Bridges RJ, Rummel W. The role of the 
paracellular pathway in the net transport of calcium across the colonic mucosa. Naunyn Schmiedebergs Arch Pharmacol. 1986;334(4):525-530.

36. Petith MM, Wenger JR, Schedl HP. Vitamin D dependence and aboral gradient of in vivo intestinal calcium transport in the rat. Am J Dig Dis. 1978;23(10):943-947.

37. Duflos C, Bellaton C, Pansu D, Bronner F. Calcium solubility, intestinal sojourn time and paracellular permeability codetermine passive calcium absorption in rats. J Nutr. 1995;125(9):2348-2355.

38. Sandle GI, Wills NK, Alles W, Binder HJ. Electrophysiology of the human colon: evidence of segmental heterogeneity. Gut. 1986;27(9):999-1005.

39. Geall MG, Spencer RJ, Phillips SF. Transmural electrical potential difference of the human colon. Gut.1969;10(11):921-923.

40. Bhojani N, et al. Nephrocalcinosis in calcium stone formers who do not have systemic disease. JUrol. 2015;194(5):1308-1312.

41. Letavernier E, et al. Demographics and characterization of 10,282 Randall plaque-related kidney stones: a new epidemic? Medicine (Baltimore). 2015;94(10):e566.

42. Evan AP, Worcester EM, Coe FL, Williams J Jr., Lingeman JE. Mechanisms of human kidney stone formation. Urolithiasis. 2015;43(suppl 10):19-32.

43. Huguet L, et al. High frequency and wide range of human kidney papillary crystalline plugs. Urolithiasis. 2018;46(4):333-341.

44. Wei G, Rosen S, Dantzler WH, Pannabecker TL. Architecture of the human renal inner medulla and functional implications. Am J Physiol Renal Physiol. 2015;309(7):F627-F637.

45. Hsi RS, Ramaswamy K, Ho SP, Stoller ML. The origins of urinary stone disease: upstream mineral formations initiate downstream Randall's plaque. BJU Int. 2017;119(1):177-184.

46. Verrier C, et al. Topography, composition and structure of incipient Randall plaque at the nanoscale level. J Urol. 2016;196(5):1566-1574.

47. Sherer BA, et al. A continuum of mineralization from human renal pyramid to stones on stems. Acta Biomater. 2018;71:72-85.

48. Asplin JR, Mandel NS, Coe FL. Evidence of calcium phosphate supersaturation in the loop of Henle. Am J Physiol. 1996;270 (4 pt 2):F604-F613.

49. Worcester EM, Coe FL. Evidence for altered renal tubule function in idiopathic calcium stone formers. Urol Res. 2010;38(4):263-269.

50. Coe FL, Evan A, Worcester E. Pathophysiology-based treatment of idiopathic calcium kidney stones. Clin J Am Soc Nephrol. 2011;6(8):2083-2092.

51. Tournus M, Seguin N, Perthame B, Thomas SR, Edwards A. A model of calcium transport along the rat nephron. Am J Physiol Renal Physiol. 2013;305(7):F979-F994.

52. Nijenhuis T, Vallon $\mathrm{V}$, van der Kemp AW, Loffing J, Hoenderop JG, Bindels RJ. Enhanced passive $\mathrm{Ca}^{2+}$ reabsorption and reduced $\mathrm{Mg}^{2+}$ channel abundance explains thiazide-induced hypocalciuria and hypomagnesemia. JClin Invest. 2005;115(6):1651-1658.

53. Tordoff MG, Bachmanov AA, Reed DR. Forty mouse strain survey of voluntary calcium intake, blood calcium, and bone mineral content. Physiol Behav. 2007;91(5):632-643.

54. Rievaj J, Pan W, Cordat E, Alexander RT. The $\mathrm{Na}^{+} / \mathrm{H}^{+}$exchanger isoform 3 is required for active paracellular and transcellular $\mathrm{Ca}^{2+}$ transport across murine cecum. Am J Physiol Gastrointest Liver Physiol. 2013;305(4):G303-G313.

55. Zelenchuk LV, Hedge AM, Rowe PS. SPR4-peptide alters bone metabolism of normal and HYP mice. Bone. 2015;72:23-33.

56. Martin DL, DeLuca HF. Influence of sodium on calcium transport by the rat small intestine. $\mathrm{Am} J$ Physiol. 1969;216(6):1351-1359.

57. Ryan ZC, et al. Deletion of the intestinal plasma membrane calcium pump, isoform 1, Atp2b1, in mice is associated with decreased bone mineral density and impaired responsiveness to 1 , 25-dihydroxyvitamin D3. Biochem Biophys Res Commun. 2015;467(1):152-156.

58. Günzel D, et al. Claudin-10 exists in six alternatively spliced isoforms that exhibit distinct localization and function. JCell Sci. 2009;122(pt 10):1507-1517.

59. Plain A, et al. Corticomedullary difference in the effects of dietary $\mathrm{Ca}^{2+}$ on tight junction properties in thick ascending limbs of Henle's loop. Pflugers Arch. 2016;468(2):293-303.

60. Nagai A, et al. Overview of the BioBank Japan Project: study design and profile. JEpidemiol. 2017;27(3 suppl):S2-S8.

61. Hirata M, et al. Overview of BioBank Japan follow-up data in 32 diseases. JEpidemiol. 2017;27(3S):S22-S28.
62. Tsugane S, Sobue T. Baseline survey of JPHC study - design and participation rate. Japan Public Health Center-based Prospective Study on Cancer and Cardiovascular Diseases. JEpidemiol. 2001;11(6 suppl):S24-S29.

63. Hamajima N, J-MICC Study Group. The Japan Multi-Institutional Collaborative Cohort Study (J-MICC Study) to detect gene-environment interactions for cancer. Asian Pac J Cancer Prev. 2007;8(2):317-323.

64. Kuriyama S, et al. The Tohoku Medical Megabank Project: design and mission. J Epidemiol. 2016;26(9):493-511.

65. Matsuo $\mathrm{K}$, et al. The aldehyde dehydrogenase 2 (ALDH2) Glu504Lys polymorphism interacts with alcohol drinking in the risk of stomach cancer. Carcinogenesis. 2013;34(7):1510-1515.

66. Tanikawa C, et al. GWAS identifies two novel colorectal cancer loci at 16q24.1 and 20q13.12. Carcinogenesis. 2018;39(5):652-660.

67. Kanai M, et al. Genetic analysis of quantitative traits in the Japanese population links cell types to complex human diseases. Nat Genet. 2018;50(3):390-400.

68. Scott LJ, et al. A genome-wide association study of type 2 diabetes in Finns detects multiple susceptibility variants. Science. 2007;316(5829):1341-1345.

69. Howie B, Fuchsberger C, Stephens M, Marchini J, Abecasis GR. Fast and accurate genotype imputation in genome-wide association studies through pre-phasing. Nat Genet. 2012;44(8):955-959.

70. Low SK, et al. Identification of six new genetic loci associated with atrial fibrillation in the Japanese population. Nat Genet. 2017;49(6):953-958.

71. Price AL, Patterson NJ, Plenge RM, Weinblatt ME, Shadick NA, Reich D. Principal components analysis corrects for stratification in genome-wide association studies. Nat Genet. 2006;38(8):904-909.

72. Willer CJ, Li Y, Abecasis GR. METAL: fast and efficient meta-analysis of genomewide association scans. Bioinformatics. 2010;26(17):2190-2191.

73. Breslow NE, Day NE. Statistical methods in cancer research. Volume II - The design and analysis of cohort studies. IARC Sci Publ. 1987;(82):1-406.

74. GTEx Consortium, et al. Genetic effects on gene expression across human tissues. Nature. 2017;550(7675):204-213. 